NOTICE : this is the author's version of a work that was accepted for publication in Composites Science and Technology. Changes resulting from the publishing process, such as peer review, editing, corrections, structural formatting, and other quality control mechanisms may not be reflected in this document. Changes may have been made to this work since it was submitted for publication. A definitive version was subsequently published in Composites Science and Technology (2008), doi:10.1016/j.compscitech.2008.06.018.

\title{
A review and analysis of electrical percolation in carbon nanotube polymer composites
}

\author{
Wolfgang Bauhofer ${ }^{1}$, Josef Z. Kovacs \\ Institut für Optische und Elektronische Materialien, Technische Universität Hamburg-Harburg, D-21073 \\ Hamburg, Germany
}

\begin{abstract}
We review experimental and theoretical work on electrical percolation of carbon nanotubes (CNT) in polymer composites. We give a comprehensive survey of published data together with an attempt of systematization. Parameters like CNT type, synthesis method, treatment and dimensionality as well as polymer type and dispersion method are evaluated with respect to their impact on percolation threshold, scaling law exponent and maximum conductivity of the composite. Validity as well as limitations of commonly used statistical percolation theories are discussed, in particular with respect to the recently reported existence of a lower kinetic (allowing for re-aggregation) and a higher statistical percolation threshold.
\end{abstract}

Keywords: Carbon nanotubes, Nano composites, Polymer-matrix composites (PMCs), Electrical properties

\section{Introduction}

Electrical percolation in mixtures of electrically conducting and non-conducting materials is a widely investigated field which has been covered by several textbooks [1],2]. The observation of a conductivity threshold in polymer/carbon nanotube (CNT) composites [3] has triggered world-wide activities in this area. A recent synopsis has been given by Winey et al. [4].

By now, almost 200 publications report on the electrical percolation threshold of CNT in different polymer systems. The variation of many parameters like CNT type, synthesis method, treatment and dimensionality as well as polymer type and dispersion method, however, impeded a thorough understanding of the processes involved. This article is an attempt to condense a comprehensive collection of published data in order to extract general dependencies of the percolation threshold, the scaling law exponent and the maximal conductivity on the above mentioned parameters.

\footnotetext{
${ }^{1}$ Corresponding author. Tel.: +49 4042878 3047; Fax: +49 4042878 2229. E-mail address: bauhofer@tuhh.de (Prof. Dr. rer. nat. W. Bauhofer).
} 


\section{Percolation thresholds}

Since the early observation of percolation-dominated electrical conductivity in a CNT/PmPV composite by Coleman et al. [3] more than 30 polymer matrices have been investigated with respect to percolation of CNT filler loading. Table 1 represents a comprehensive collection of published data in this field. The table is organized as follows: The polymer matrices in column 1 are arranged alphabetically, the data for a given polymer are arranged with increasing percolation threshold. The acronyms used to denote the polymers are defined below the table. Type (single/double/multi wall), synthesis method (arc discharge, chemical vapor deposition, laser vaporization), manufacturer, state (entangled or non-entangled), additional treatment (purification, functionalization) and aspect ratio of the CNT are given in columns 2-5 as far as the information is available from the publications. In columns 6 and 7 dispersion method and solvent in the case of solution processing are specified. Finally, electrical characteristics like percolation threshold $\Phi_{\mathrm{C}}$, critical exponent $\mathrm{t}$ and maximum observed conductivity $\sigma_{\max }$ are listed in columns 8-10. All percolation thresholds and filler concentrations are given in weight\% (wt\%). Wherever the original data are given in vol\%, we use the conversion relations vol $\%=w t \%$ for single wall nanotubes $($ SWCNT) and vol $\%=2 \mathrm{wt} \%$ for multi wall nanotubes (MWCNT) independent of the polymer matrix. We are convinced that the resulting inaccuracies have no significant effect on the interpretation of the experimental results.

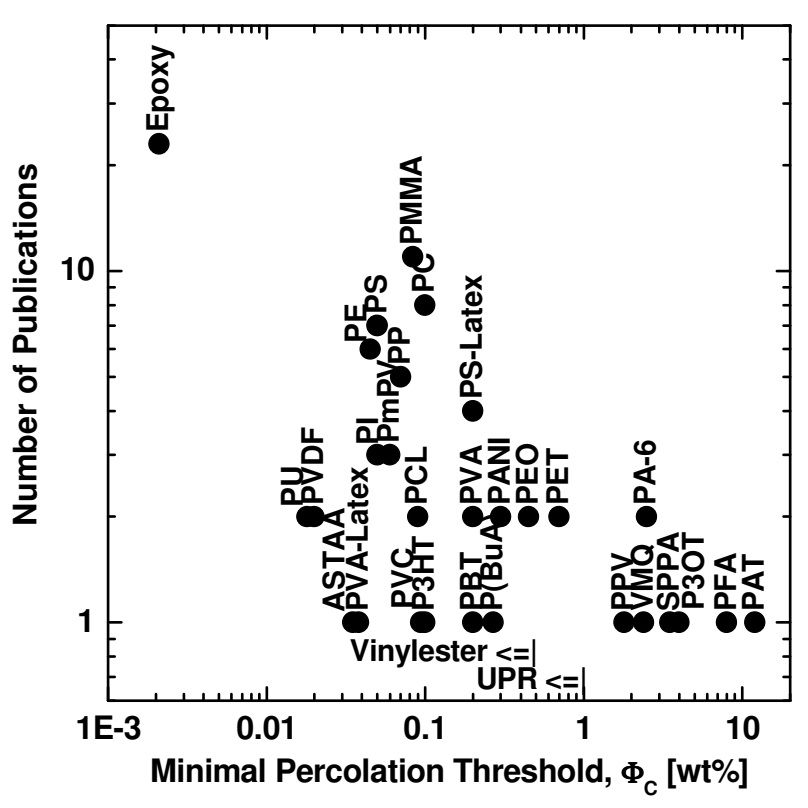

Fig. 1. Plot of the total number of publications per polymer system versus the minimum percolation threshold achieved with the respective system.
Inspection of Table 1 clearly shows a large spread in the number of investigations for different polymer matrices. For 14 polymers listed in the table a single publication was available to us while 23 papers referring to an epoxy matrix could be included. This imbalance has to be taken into account when evaluating Table 1 with respect to percolation thresholds $\Phi_{C}$. This fact is visualized by Fig. 1, which shows the minimum observed $\Phi_{C}$ together with the number of publications for each polymer matrix. We notice that for all $\Phi_{\mathrm{C}}>0.2 \mathrm{wt} \%$ no more than two papers could be exploited. This finding supports our belief that with optimized dispersion methods a percolation threshold $\Phi_{\mathrm{C}} \approx 0.1$ wt $\%$ might be obtainable for nearly any

CNT/polymer system. For a statistical distribution of filler particles the excluded volume concept [5] gives $\Phi_{C} \approx 1 / \eta$ in the limit of large aspect ratios $\eta$. A typical aspect ratio $\eta \approx 1000$ for CNT reproduces the above mentioned value of $0.1 \mathrm{wt} \%$. Thus, we relate 
this value to the statistical percolation threshold. Percolation thresholds significantly lower than $\Phi_{\mathrm{C}} \approx 0.1 \mathrm{wt} \%$ are attributed to kinetic percolation which allows for particle movement and re-aggregation. This interpretation particularly applies to results published for CNT/epoxy composites [6],7].

The observation of two percolation thresholds in the same MWCNT/epoxy system was recently reported by Kovacs et al. [8]. Statistical percolation refers to a situation where randomly distributed filler particles form percolating paths. In kinetic percolation, the particles are free to move and thereby can form a conducting network at much lower particle concentrations. Particle movement can be caused by diffusion, convection, shearing, or external fields. Figure 2 shows the cured sample conductivity vs. filler concentration for three different methods of sample preparation: slow (50 rpm), medium (500 $\mathrm{rpm})$, and fast $(2000 \mathrm{rpm})$ stirring of the dispersion for $5 \mathrm{~min}$ at elevated temperature $\left(80{ }^{\circ} \mathrm{C}\right)$ prior to curing. Fast stirring leads to statistical percolation near $0.1 \mathrm{wt} \%$. Slow or medium stirring

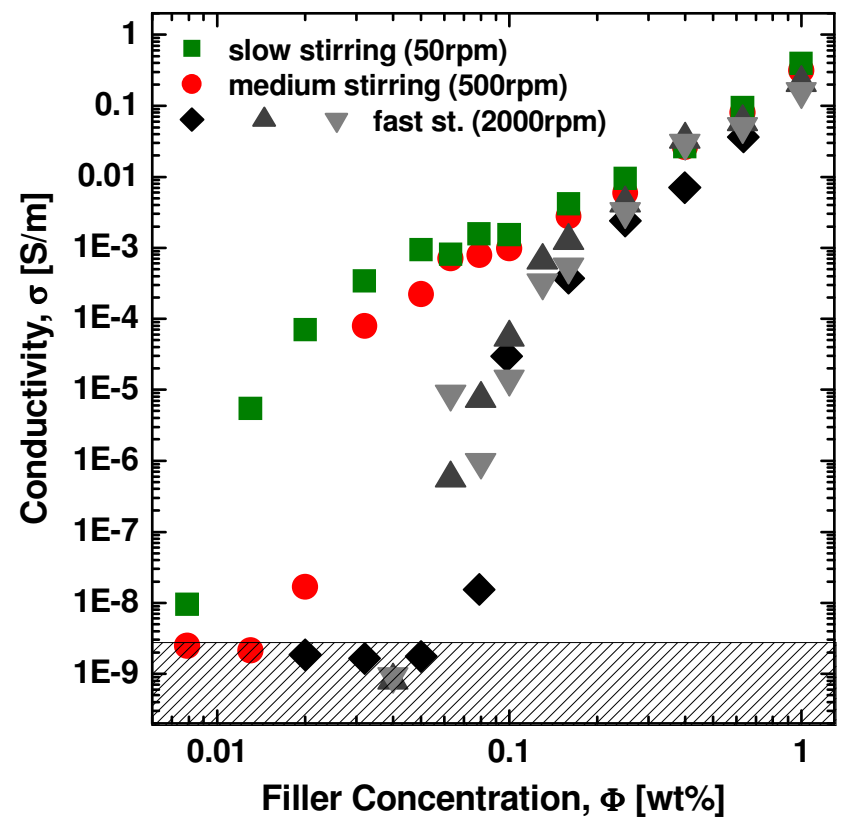

Fig. 2. Comparative log-log plot of the nanocomposite (MWCNT/epoxy) conductivity as a function of the nanotube weight fraction for the three different sample preparation methods: slow (50 rpm), medium (500 rpm), and fast (2000 rpm) stirring of the dispersion for 5 minutes at elevated temperature $\left(80^{\circ} \mathrm{C}\right)$ prior to curing. induce aggregation of CNT and, thereby, lead to kinetic percolation at significantly lower filler concentrations. However, when the filler concentration approaches the statistical percolation threshold, the effect of stirring and thereby the effect of particle movement vanishes. This effect manifests itself by a change in slope around $0.1 \mathrm{wt} \%$ in the conductivity curve for slow and medium stirring.

While stirring produces a rather complicated shear state, controlled shear can be applied to a CNT/polymer suspension in a rheometer. Rheo-optical studies of flow-induced clustering of CNT have first been reported by Erik Hobbie's group at NIST [9] using MWCNT/polyisobutylene suspensions. Rheological measurements and associated optical microstructural observations of MWCNT suspended in epoxy have been described by Rahatekar et al. [10]. Incorporation of $0.35 \mathrm{wt} \%$ MWCNT enhanced the low shear rate viscosity by a factor of 20 . At higher shear rates, the suspension viscosity asymptotically thinned to the viscosity of the matrix alone. The authors conjecture that shear thinning is connected with the breaking of interconnected networks between CNT and/or aggregates of CNT, and not by CNT alignment. However, at low concentrations $(0.035 \mathrm{wt} \%)$ aligning was observed instead of macroscopic aggregate formation. We 
have observed shear induced aggregation also for low concentrations, as depicted in Fig. 3.
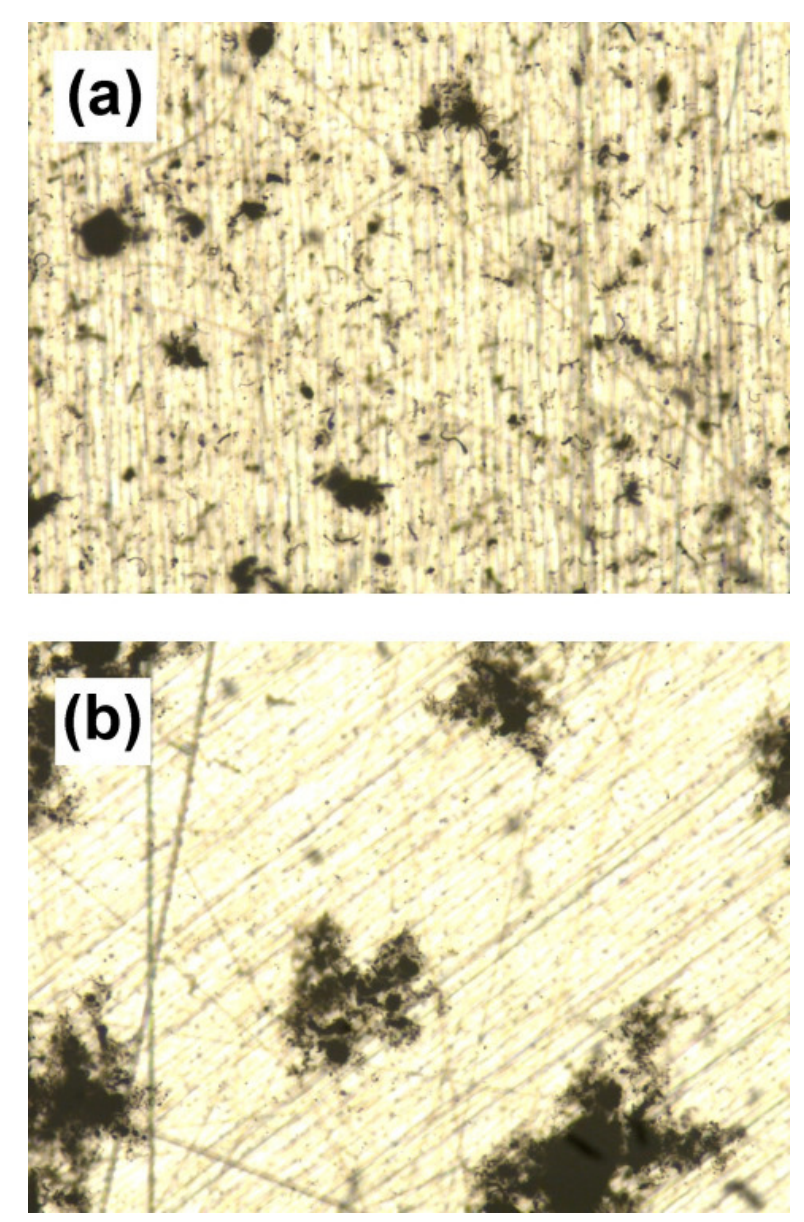

Fig. 3. Optical micrographs of a liquid epoxy composite containing $0.05 w t \%$ MWCNT in the initial, dispersed state (a) and after shearing with $0.1 \mathrm{~s}^{-1}$ at $70^{\circ} \mathrm{C}$ for 60 minutes (b). The width of the image is $1 \mathrm{~mm}$.

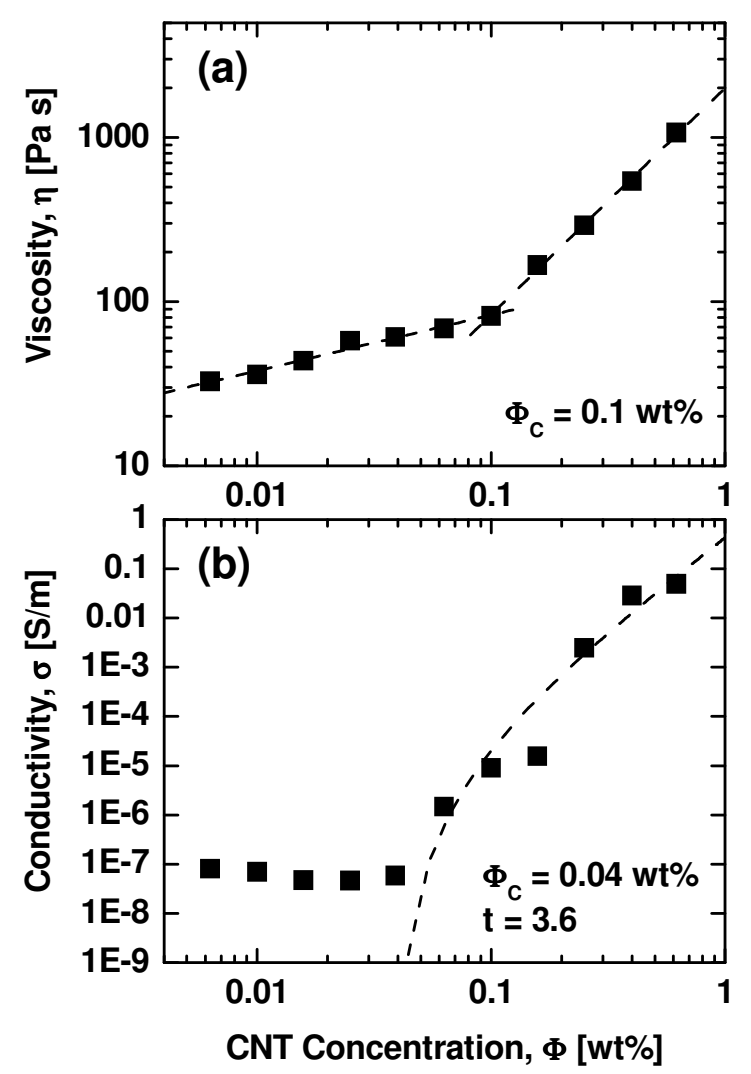

Fig. 4. Simultaneous measurement of the nanocomposite (MWCNT/epoxy) viscosity (a) and electrical conductivity (b) as function of the nanotube weight fraction, performed in the liquid state prior to curing at $0.1 \mathrm{~s}^{-1}$ and $20^{\circ} \mathrm{C}$. The rheological percolation threshold is located at 0.1 $w t \%$ and the electrical one at $0.04 w t \%$.

Contradicting results have been published concerning the dependence of the percolation threshold on the aspect ratio. According to the excluded volume analysis of Celzard et al. [11] the percolation threshold of a fiber suspension should decrease with increasing aspect ratio. The results of Bai et al. [12] yield a decreasing percolation threshold with increasing CNT length while Martin et al. [13] find an increasing percolation threshold with increasing CNT length. This inconsistency may be solved when looking at the type of the respective percolation thresholds. Bai et al. most likely obtained statistical thresholds while Martin et al. definitely achieved kinetic percolation. Since all theoretical analyses so far ignore the movement of filler particles, they can only predict the dependence of the statistical percolation threshold on the filler aspect ratio.

The effect of CNT alignment on percolation conductivity in SWCNT/PMMA composites has been investigated by Du et al. [14]. The SWCNT were aligned by melt fiber spinning, various levels of alignment could be obtained by controlling the extensional flow in the 
spinning process. As a function of alignment the conductivity exhibits a power-law behavior. Highest conductivities occur for slightly aligned, rather than isotropic CNT. A theoretical investigation of the effects of CNT alignment on percolation resistivity using Monte Carlo simulations was recently published by Behnam et al. [15]: Minimum resistivity occurred for a partially aligned rather than a perfectly aligned nanotube film.

The dependences of rheological parameters on filler concentration yield a rheological percolation threshold which, in general, occurs at lower concentrations than electrical percolation. Filler particles can interact with each other via polymer chains whereas direct contact between them is required for electrical conduction. For the thermoplastic system SWNT/PMMA, Du et al. [16] indeed observe a rheological threshold at $0.12 \mathrm{wt} \%$ well below the electrical threshold at $0.39 \mathrm{wt} \%$. A complementary behavior is found for the thermoset system MWNT/epoxy (see Fig. 4). Due to the lack of polymer chains in the liquid state of thermoset systems, the electrical percolation threshold is encountered first, at around $0.04 \mathrm{wt} \%$. Rheological percolation is reached at $0.1 \mathrm{wt} \%$, where a strong physical interaction between the filler particles is ensured.

\section{Maximum conductivities}

Maximum conductivities of $10,000 \mathrm{~S} / \mathrm{m}$ have been reported for PMMA containing $10 \mathrm{wt} \%$ $\mathrm{SOCl}_{2}$ treated SWCNT [17], of $3000 \mathrm{~S} / \mathrm{m}$ for PANI filled with $15 \mathrm{wt} \%$ SWCNT [18], and of $2000 \mathrm{~S} / \mathrm{m}$ for PU with $15 \mathrm{wt} \%$ MWCNT [19]. ${ }^{2}$ The percolation thresholds found for the above mentioned systems, i.e., $0.17 \mathrm{wt} \%, 0.3 \mathrm{wt} \%$, and $1 \mathrm{wt} \%$, respectively, suggest a correlation between percolation threshold and maximum conductivity ${ }^{3}$. Indeed, this finding seems to be true especially for composites based on the same matrix system. It is worth mentioning that the conductivity of composites with identical filler concentration seems to vary - with some exceptions - by only one or two orders of magnitude for identical matrices, but by 10 or more orders of magnitude for different matrices.

We first address the conductivity variation caused by different fillers in the same matrix. Interestingly, type (SWCNT or MWCNT) and treatment (purification, oxidation) of the nanotubes do not show a clear impact on the maximum conductivity (see Table 1). In Fig. 5 the maximum conductivities of all reviewed data are plotted versus their respective filler concentration value. We want to point out that the maximum conductivities of Fig. 5 refer to the maximum values reported in a given publication. In general, these values are significantly lower than conductivities obtained at the maximum attainable concentrations with a respective polymer and processing method.

\footnotetext{
${ }^{2}$ Even higher conductivities can be found in publications that do not analyze the electrical percolation threshold or that report on conductive polymer matrices like protonated PANI. These publications are not considered in our review.

${ }^{3}$ The plot (not shown) of the maximum conductivities versus the percolation thresholds has to be subdivided into data sets of comparable CNT concentrations, as the reported maximum concentrations and thus the maxumim conductivities vary considerably even for similar percolation thresholds. Within each data set an indirect proportionality between the maximum conductivities and the percolation thresholds could be identified.
} 


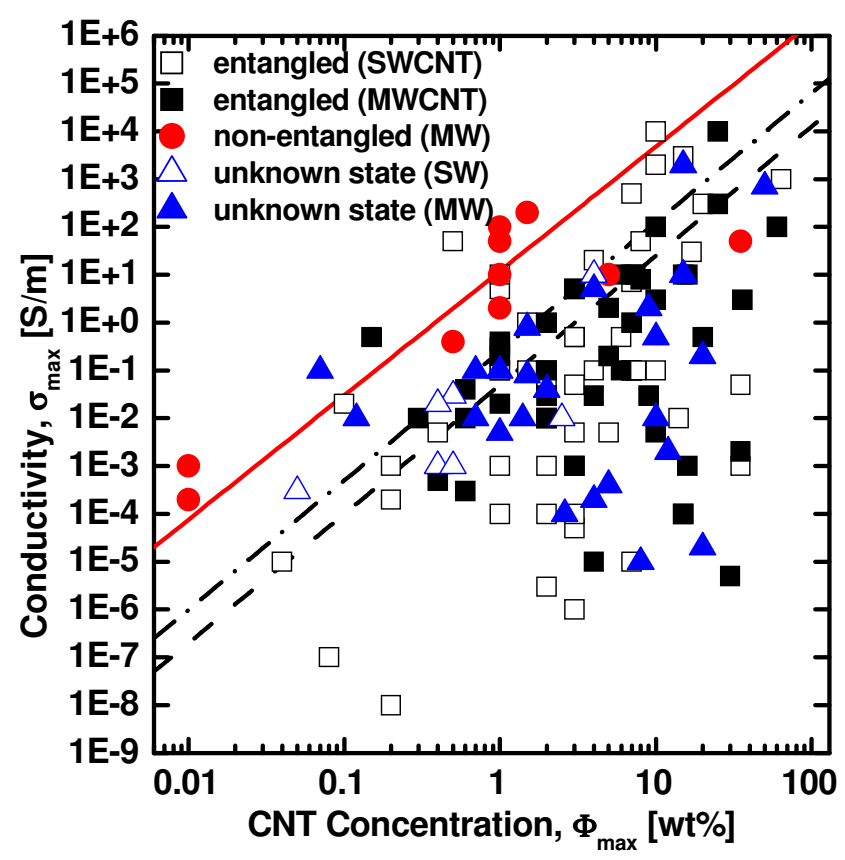

Fig. 5. Comparative log-log plot of maximum conductivity versus respective CNT concentration for all the data in Table 1. The dash-dotted line denotes the dependence $\sigma=2500 \cdot \Phi^{2.7} \mathrm{~S} / \mathrm{m}$ found for entangled MWCNT in an epoxy matrix [8] while the solid line indicates a similar dependence $\sigma=$ $120000 \cdot \Phi^{2.6}$ found for non-entangled MWCNT in the same matrix system (unpublished). All data below the dashed line $\left(\sigma=500 \cdot \Phi^{2.7} \mathrm{~S} / \mathrm{m}\right.$ for low conductive CNT) are most likely dominated by tunneling between the CNT.

The data points spread over a wide conductivity and concentration range, but principally stay below the dash-dotted line. There are some exceptions, most of them at concentrations above $10 \mathrm{wt} \%$, where a homogeneous suspension probably is not reached. The dash-dotted line denotes the dependence $\sigma=$ $2500 \cdot \Phi^{2.7} \mathrm{~S} / \mathrm{m}$ found in [8] for entangled MWCNT in an epoxy matrix above the statistical percolation threshold. This line seems to represent the maximum achievable conductivities for entangled MWCNT that are widespread in composite research as their production is fast and cheap. Unpublished results from Kovacs et al. on non-entangled MWCNT (that grow like trees in a forest) show similar power law dependencies above the statistical percolation threshold, the conductivities however are shifted upwards by a factor of 50 (solid line). These findings as well as results of other groups on various matrix systems (see Table 1) suggest that non-entangled MWCNT give much higher composite conductivities than entangled ones. This difference can be explained in two alternative ways. Either the entangled MWCNT could not be dispersed homogeneously and therefore their intrinsic conductivity cannot be extracted from a formula like $\sigma \approx \sigma_{0} \cdot \Phi^{t}$. Or, the intrinsic conductivities of entangled and non-entangled MWCNT truly differ by a factor of 50 (possibly because the straight growing non-entangled MWCNT are less defective). Taking $500 \mathrm{~S} / \mathrm{m}$ as a lower conductivity limit for highly defective MWCNT we still find many reported data below the dashed line $\left(\sigma=500 \cdot \Phi^{2.7} \mathrm{~S} / \mathrm{m}\right)$. In these cases, we most probably have to consider tunneling through polymer barriers between CNT. Comparing the shift (from one line to another) attributed to different intrinsic nanotube conductivities with the conductivity scattering below the dashed line we conclude that polymer tunneling barriers have a dominant effect on the overall composite conductivity. Definite conclusions on how to avoid this polymer sheathing and maximize conductivity cannot be drawn from the analyzed data. As good dispersions usually imply the formation of a polymer layer around each CNT, we believe that the best dispersions not necessarily lead to the highest conductivities. It seems that solvent processing techniques [88] or shear induced re-aggregation [8] sometimes improve the electrical performance of composites by preventing an overall sheathing or reducing the sheath thickness, respectively. 
Comparing different matrices the conductivity variations are much higher than for different fillers. Again, this can only be explained with the extreme distance dependence of tunneling through polymer barriers between CNT. It seems that some polymer types and processing methods favor the formation of insulating polymer coatings of different thicknesses on the CNT. According to Connor et al. [20] tunneling between CNT separated by a thin isolating layer should lead to a dependence of the form

$$
\ln \sigma_{D C} \sim-\Phi^{-1 / 3}
$$

between DC conductivity and filler load. A number of investigations seem to confirm this relation. However, as shown in Fig. 6 and discussed in [8], an unambiguous determination of the exponent is not possible.

The mechanism of charge transport in CNT/polymer composites has also been addressed by temperature dependent conductivity measurements. Kim et al. [21] have fitted their experimental results to different theoretical dependencies derived by Mott [22] and by Sheng et al. [23] based on variable range hopping in the former case and fluctuation induced tunneling in the latter. Again, an unambiguous assignment seems difficult.

\section{Theoretical approaches}

The concept of excluded volume has proven to be a powerful method to estimate the percolation threshold of composites containing statistically dispersed non-spherical particles. The concept is based on the idea that the percolation threshold is not linked to the true volume of the filler particles but rather to their excluded volume $V_{\text {ex }}$. The excluded volume is defined as the volume around an object in which the center of another similarly shaped object is not allowed to penetrate [24]. $\left\langle\mathrm{V}_{\mathrm{ex}}>\right.$ represents the excluded volume of an object averaged over the orientational distribution characterizing the system objects.

For randomly oriented cylinders with volume $V=W^{2} L \pi / 4$ and high aspect ratio $\eta=L / W$,

$$
<\mathrm{V}_{\mathrm{ex}}>\approx \mathrm{WL}^{2} \pi / 2
$$
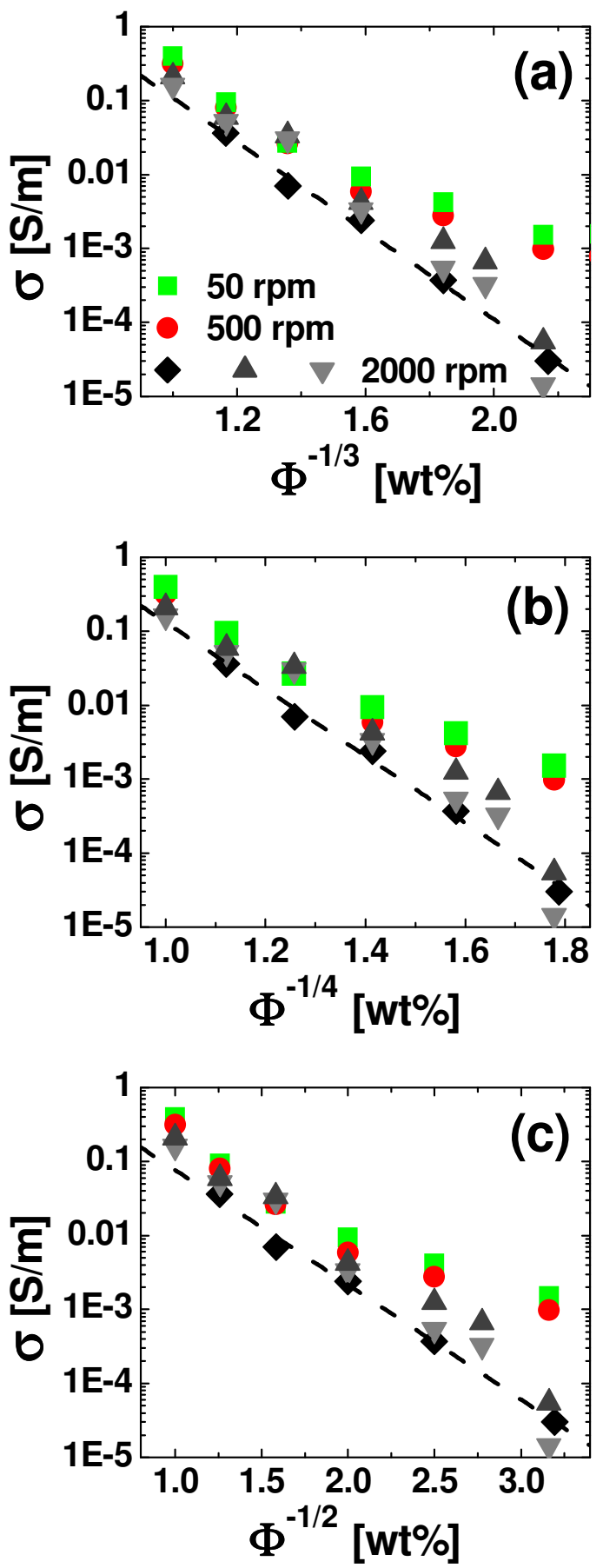

Fig. 6. Plot of the conductivity data from Fig. 2. as a function of (a) $\Phi^{-1 / 3}$, (b) $\Phi^{-1 / 4}$ and (c) $\Phi^{-1 / 2}$. 

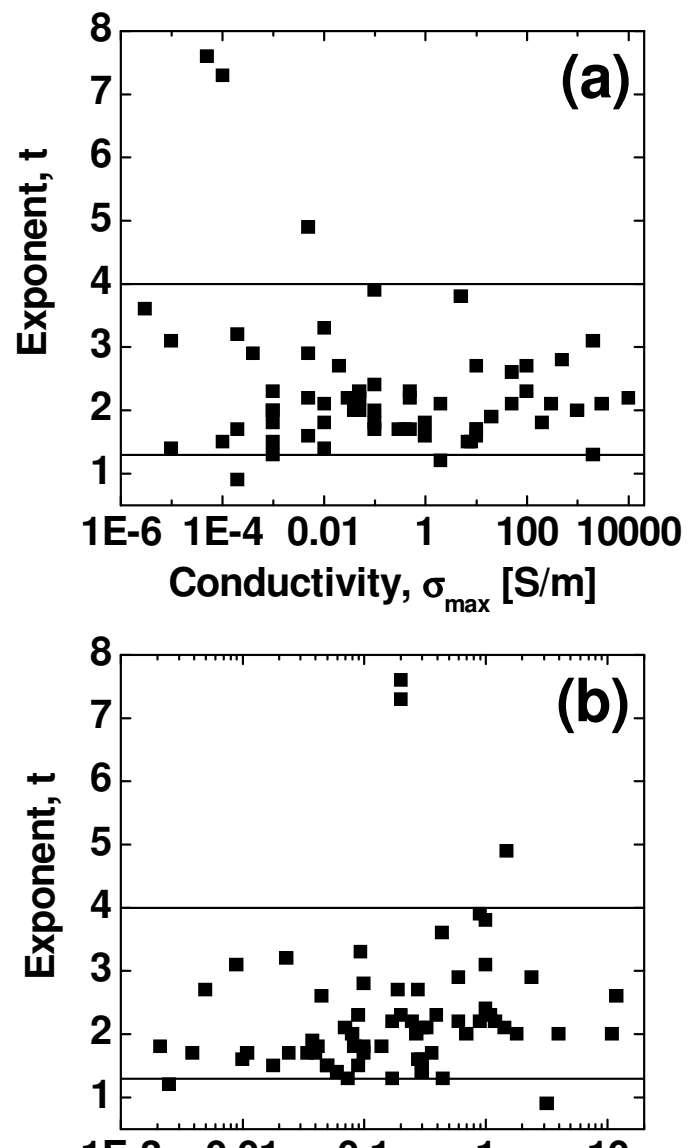

$\begin{array}{lllll}1 \mathrm{E}-3 & 0.01 & 0.1 & 1 & 10\end{array}$

Percolation Threshold, $\Phi_{\mathrm{C}}[w t \%]$

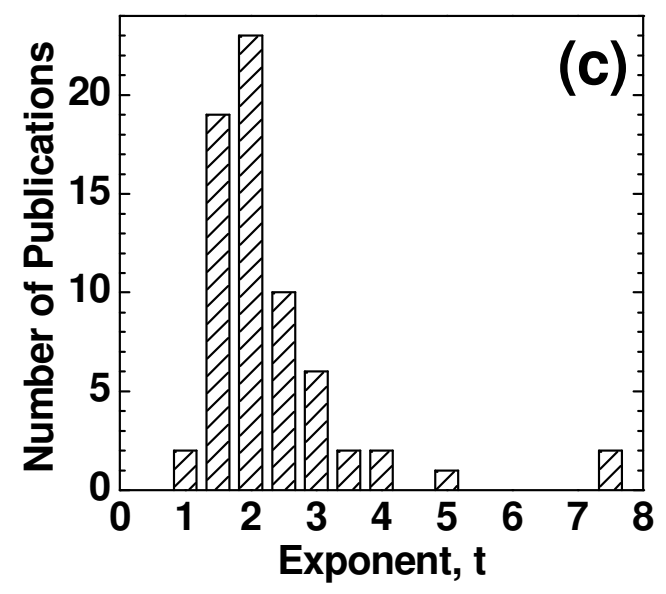

Fig. 7. Plot of the power law exponent $t$ as a function of (a) the maximum conductivity and (b) the percolation threshold for all data in Table 1. The horizontal lines denote $t=1.3$ and 4 . Fig. 7 (c) shows a histogram of $t$ values. and

$$
\Phi_{\mathrm{C}} \sim \mathrm{V} /<\mathrm{V}_{\mathrm{ex}}>=\mathrm{W} /(2 \mathrm{~L})=1 /(2 \eta)
$$

or

$$
\Phi_{\mathrm{C}} \approx 0.7 / \eta \quad[11] \text {. }
$$

As already mentioned in Section 2, reported values for the statistical percolation threshold $\Phi_{C}$ agree very well with the above considerations.

From electron microscopy it became evident that CNT embedded in a polymer matrix generally are curved or wavy rather than straight [25]. The effect of waviness on percolation has been addressed by a couple of authors using different theoretical approaches [26]-29]. They all find the obvious result that the percolation threshold increases with increasing waviness of the CNT. However, in all calculations the increase in $\Phi_{C}$ remains well below a factor of 2 which means that the effect of waviness can be considered as small in the context of Table 1.

Frequently, CNT are dispersed in form of bundles. The effect of bundles on percolation has been calculated by Grujicic et al. [30]. As expected, the percolation threshold increases with increasing bundle radius.

Statistical percolation theory predicts for the dependence of conductivity on filler concentration a scaling law of the form

$$
\sigma=\sigma_{0} \cdot\left(\Phi-\Phi_{\mathrm{C}}\right)^{\mathrm{t}} \text {. }
$$

Usually, experimental results are fitted by plotting log $\sigma$ vs log $\left(\Phi-\Phi_{\mathrm{C}}\right)$ and incrementally varying $\Phi_{C}$ until the best linear fit is obtained [95]. The critical exponent $t$ is expected to depend on the system dimensionality with calculated values of $t \approx 1.33$ in two and $t \approx 2$ in three dimensions $[1,2]$. A value of $t \approx 3$ has been obtained for $a$ Bethe lattice and within mean field theory whereas a value of $t \approx 2.5$ has been derived within a continuum model, the "Swiss cheese model" [1], which simulates distributed bond strengths or contact resistances. Similar results have been achieved by Balberg [31] allowing a nonrandom distribution of voids in random void models of continuum percolation. 
As shown in Fig. 7, fits to experimental data for CNT/polymer composites yield values of t predominantly in the range from 1.3 to 4 peaking around $t=2$ (Fig. $7 \mathrm{c}$ ). The above mentioned theories relate increasing values of $t$ to increasing tunneling barriers between the fillers which would lead to low maximum composite conductivities. As visible in Fig. 7 (a), such a dependency is not found in the evaluated publications. Experiments by Kovacs et al. [8] carried out with the same system suggest a change in t from low values $(\sim 1.7)$ in the case of low (kinetic) percolation thresholds to high values $(\sim 2.3)$ in the case of higher (statistical) percolation. Fig. 7 (b) however does not reflect such a relation between the percolation threshold and the magnitude of $t$.

It seems rather complicated to extract geometrical information about the CNT network from experimentally determined values of $t$. We believe that such a procedure is generally not justified. First of all, scaling is limited to a concentration range very close to the percolation threshold. However, this range of validity has not been examined in detail for CNT/polymer composites. In addition, the results of statistical percolation theory are derived for ideal systems which contain a homogeneous dispersion of identical particles. Due to the spread in CNT properties, i.e., length, diameter, chirality, entanglement and waviness, CNT/polymer composites are far away from being ideal systems. A further complication arises from the fact that low percolation thresholds are likely to be kinetically produced, which makes the application of statistical percolation theory questionable.

Modeling of kinetic percolation requires complex and time-consuming calculations. Rahatekar et al. [32] applied dissipative particle dynamics (DPD) to investigate the dynamic behavior of an assembly of oriented fibers suspended in a viscous medium. After establishing the structural arrangement the fiber network impedance was assessed using Monte Carlo simulations. In future work the effects of polydispersity in fiber properties, of electrostatic interaction of fibers, and of shear forces on percolation threshold shall be studied. Wescott et al. [33] used DPD simulations to investigate methods of controlling the assembly of percolating networks of CNT in thin films of block copolymer melts. For suitably chosen parameters the CNT were found to self-assemble. Finally, Tozzi et al. [34] employed particle-level simulations [35] to investigate the time evolution of the microstructure and the electrical conductivity of CNT suspensions in shear flow. The simulations allow control of numerous properties, including the matrix viscosity, nanotube aspect ratio, shape, flexibility, and interaction forces. All these approaches are important steps towards a better understanding of kinetic percolation.

\section{Electric field induced CNT network formation}

Martin et al. [36] have shown that the formation of CNT networks can be induced by the application of an external electric field. Thus, electric fields not only align CNT but also enhance the attractive forces between neighboring CNT. Figure 8 shows the formation of a CNT network induced by a DC field of $100 \mathrm{~V} / \mathrm{cm}$. The growth of the network starts at 
the positive electrode indicating that CNT are negatively charged in an epoxy/amine hardener system. As has been shown for carbon black/epoxy composites the chemical nature of the hardener mainly determines the charge of the filler particles [37]. AC fields are more effective than DC fields in the sense that the conductivity of samples cured in an $A C$ field is one order of magnitude higher than for DC fields. Compared with shear percolated composites the absolute conductivities of AC field percolated samples are still one order of magnitude lower. Conductivity anisotropies of more than $10^{4}$ have been obtained. Figure 9 shows that the conductivities of cured samples saturate as a function of field strength and as a function of filler concentration. We believe that the last mentioned observation is equivalent to the transition from kinetic to statistical percolation. When approaching statistical percolation the mobility of CNT is reduced and the effect of the electric field vanishes. The formation of $A C$ electric field induced aligned SWCNT percolative columns between electrodes has also been observed by Park et al. in SWCNT/UDMA/HDDMA composites [38].
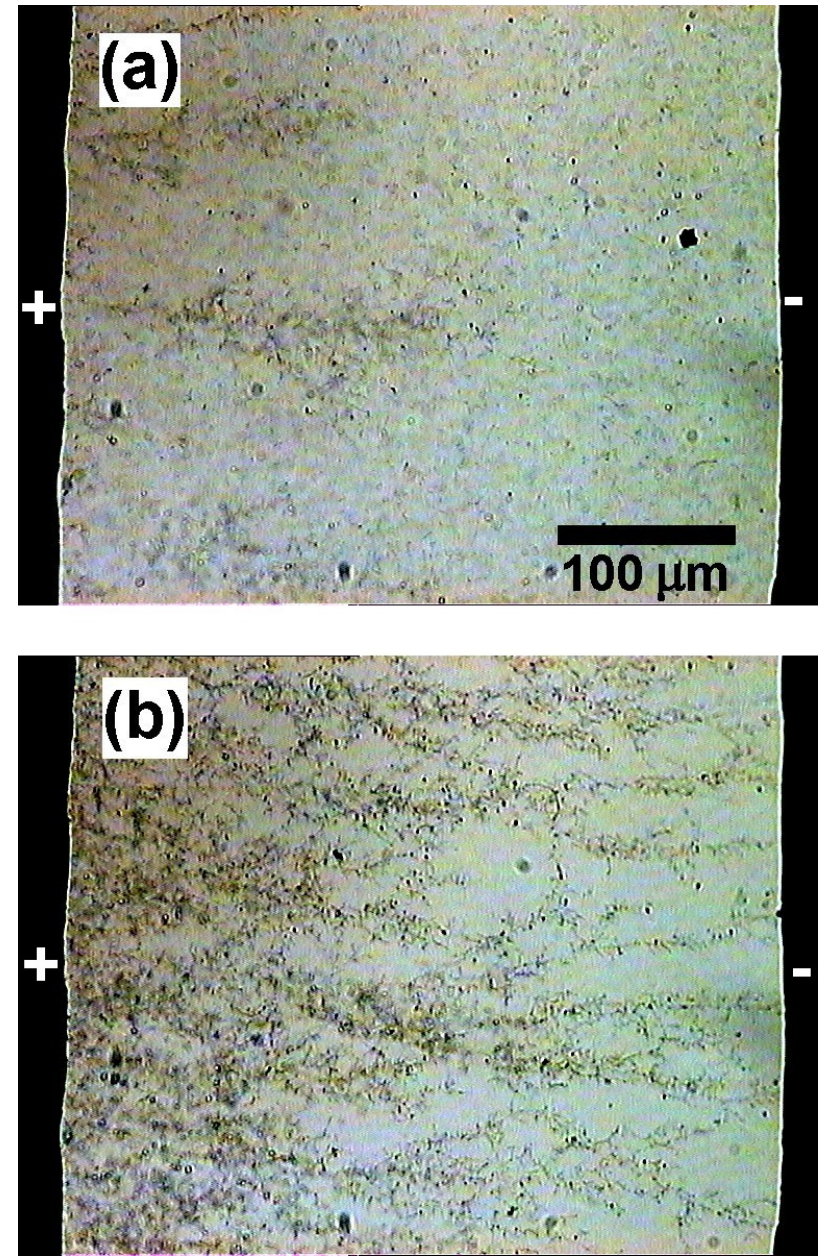

Fig. 8. Optical micrographs of a liquid epoxy composite containing 0.01 wt\% MWCNT after 5 minutes (a) and 4 hours (b) of exposure to a 100 $\mathrm{V} / \mathrm{cm} D \mathrm{C}$ electric field at $80^{\circ} \mathrm{C}$. The scale bar is 100 $\mu m$.

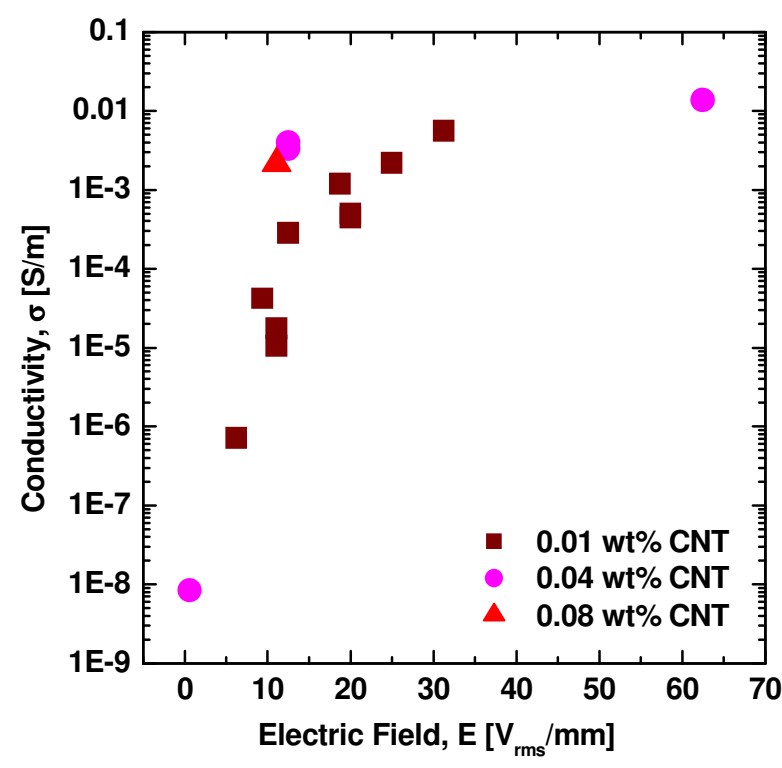

Fig. 9. Plot of the composite conductivity for various MWCNT concentrations after exposure to different $A C$ field strengths during the curing time. 


\section{Conclusion}

We reviewed 147 experimental results on electrical percolation of carbon nanotubes (CNT) in polymer composites published in 100 articles. The following conclusions can be drawn from these data:

(1) Referring to minimum percolation thresholds and maximum conductivities, type and production method of CNT seem to be less important than type of polymer and dispersion method.

(2) An indirect proportionality seems to exist between the percolation threshold and the maximally reached conductivity for given CNT concentrations and polymer matrices.

(3) Non-entangled MWCNT give conductivities 50 times higher than the usual entangled MWCNT from industrial mass production. Conductivity values below $\sigma$ $=500 \cdot \Phi^{2.7} \mathrm{~S} / \mathrm{m}$ are indicative of polymer tunneling barriers between CNT.

(4) Many polymer composites seem to reproduce the theoretically predicted dependence of the percolation threshold on the aspect ratio $\Phi_{C} \approx 1 / \eta$ once their filler particles are homogeneously distributed (statistical percolation).

(5) Deviating results with higher $\Phi_{C}$ suggest that the filler particles were not dispersed homogeneously, while lower $\Phi_{C}$ indicates the flocculation of homogeneously dispersed particles (kinetic percolation).

(6) Regarding the contradiction between the experimental results from Martin et al. [13] and the above mentioned theoretical prediction, we conclude that kinetic percolation cannot be described with statistical percolation theory.

(7) The magnitude of the percolation theory scaling law exponent $t$ could not be related to any other parameter extracted from the articles. We believe that no reliable geometrical information about the CNT network can be extracted from most of the experimentally determined values of $t$.

\section{Acknowledgments}

We acknowledge valuable discussions with Prof. Jonathan Coleman from Trinity College Dublin.

[1] Stauffer D, Aharony A. Introduction to percolation theory. London: Taylor \& Francis; 1992.

[2] Sahimi M. Applications of percolation theory. London: Taylor \& Francis; 1994.

[3] Coleman JN, Curran S, Dalton AB, Davey AP, McCarthy B, Blau W, Barklie RC. Percolationdominated conductivity in a conjugated-polymer-carbon-nanotube composite. Phys Rev B 1998;58(12):R7492-5.

[4] Winey $\mathrm{KI}$, Kasiwagi T, Mu M. Improving electrical conductivity and thermal properties of polymers by addition of carbon nanotubes as fillers. MRS Bull 2007;32(4):348-53.

[5] Balberg I, Anderson $\mathrm{CH}$, Alexander S, Wagner N. Excluded volume and its relation to the onset of percolation. Phys Rev B 1984;30(7):3933-43.

[6] Sandler JKW, Kirk JE, Kinloch IA, Shaffer MSP, Windle AH. Ultra-low electrical percolation threshold in carbon-nanotube-epoxy composites. Polymer 2003;44(19):5893-9. 
[7] Bryning MB, Islam MF, Kikkawa JM, Yodh AG. Very low conductivity threshold in bulk isotropic single-walled carbon nanotube-epoxy composites. Adv Mater 2005;17(9):1186-91.

[8] Kovacs JZ, Velagala BS, Schulte K, Bauhofer W. Two percolation thresholds in carbon nanotube epoxy composites. Compos Sci Technol 2007;67(5):922-8.

[9] Lin-Gibson S, Pathak JA, Grulke EA, Wang H, Hobbie EK. Elastic flow instability in nanotube suspensions. Phys Rev Lett 2004;92(4):48302(1-4).

[10] Rahatekar SS, Koziol KKK, Butler SA, Elliott JA, Shaffer MSP, Mackley MR, Windle AH. Optical microstructure and viscosity enhancement for an epoxy resin matrix containing multiwall carbon nanotubes. J Rheol 2006;50(5):599-610.

[11] Celzard A, McRae E, Deleuze C, Dufort M, Furdin G, Marêchê JF. Critical concentration in percolating systems containing a high-aspect-ratio filler. Phys Rev B 1996;53(10):6209-14.

[12] Bai JB, Allaoui A. Effect of the length and the aggregate size of MWNTs on the improvement efficiency of the mechanical and electrical properties of nanocomposites - experimental investigation. Compos A 2003;34(8):689-94.

[13] Martin CA, Sandler JKW, Shaffer MSP, Schwarz MK, Bauhofer W, Schulte K, Windle AH. Formation of percolating networks in multi-wall carbon-nanotube-epoxy composites. Compos Sci Technol 2004;64(15):2309-16.

[14] Du FM, Fischer JE, Winey Kl. Effect of nanotube alignment on percolation conductivity in carbon nanotube/polymer composites. Phys Rev B 2005;72(12):121404(1-4).

[15] Behnam A, Guo J, Ural A. Effects of nanotube alignment and measurement direction on percolation in single-wall carbon nanotube films. J Appl Phys 2007;102(4):44313(1-7).

[16] Du FM, Scogna RC, Zhou W, Brand S, Fischer JE, Winey KI. Nanotube networks in polymer nanocomposites: rheology and electrical conductivity. Macromolecules 2004;37(24):9048-55.

[17] Skakalova V, Dettlaff-Weglikowska U, Roth S. Electrical and mechanical properties of nanocomposites of single wall carbon nanotubes with PMMA. Synth Met 2005;152(1-3):349-52.

[18] Blanchet GB, Fincher CR, Gao F. Polyaniline nanotube composites: a high-resolution printable conductor. Appl Phys Lett 2003;82(8):1290-2.

[19] Koerner H, Liu WD, Alexander M, Mirau P, Dowty H, Vaia RA. Deformation-morphology correlations in electrically conductive carbon nanotube thermoplastic polyurethane nanocomposites. Polymer 2005;46(12):4405-20.

[20] Connor MT, Roy S, Ezquerra TA, Baltá Calleja FJ. Broadband ac conductivity of conductor-polymer composites. Phys Rev B 1998;57(4):2286-94.

[21] Kim HM, Choi MS, Joo J, Cho SJ, Yoon HS. Complexity in charge transport for multiwalled carbon nanotube and poly(methyl methacrylate) composites. Phys Rev B 2006;74(5):54202(1-7).

[22] Mott NF, Davis EA. Electronic properties in non-crystalline materials. Oxford: Clarendon; 1979.

[23] Sheng P, Sichel EK, Gittleman Jl. Fluctuation-induced tunneling conduction in carbonpolyvinylchloride composites. Phys Rev Lett 1978;40(18):1197-200.

[24] Onsager L. The Effects of shape on the interactions of colloidal particles. Ann NY Acad Sci 1949;51:627-59.

[25] Kovacs JZ, Andresen K, Pauls JR, Pardo Garcia C, Schossig M, Schulte K, Bauhofer W. Analyzing the quality of carbon nanotube dispersions in polymers using scanning electron microscopy. Carbon 2007;45(6):1279-88.

[26] Dalmas F, Dendievel R, Chazeau L, Cavaille J-Y, Gauthier C. Carbon nanotube-filled polymer composites. Numerical simulation of electrical conductivity in three-dimensional entangled networks. Acta Materialia 2006;54(11):2923-31.

[27] Berhan L, Sastry AM. Modeling percolation in high-aspect-ratio fiber systems. II. The effect of waviness on the percolation onset. Phys Rev E 2007;75(4):41121(1-7).

[28] Li C, Chou T-W. Continuum percolation of nanocomposites with fillers of arbitrary shapes. Appl Phys Lett 2007;90(17):174108(1-3).

[29] Hu N, Masuda Z, Fukunaga H. Prediction of electrical conductivity of polymer filled by carbon nanotubes. Proceedings of the 16th International Conference on Composite Materials, Kyoto, Japan, 2007. 
[30] Grujicic M, Cao G, Roy WN. A computational analysis of the percolation threshold and the electrical conductivity of carbon nanotubes filled polymeric materials. J Mater Sci 2004;39(14):4441-9.

[31] Balberg I. "Universal" percolation-threshold limits in the continuum. Phys Rev B 1985;31(6):4053-5.

[32] Rahatekar SS, Hamm M, Shaffer MSP, Elliott JA. Mesoscale modeling of electrical percolation in fiber-filled systems. J Chem Phys 2005;123(13):134702(1-5).

[33] Wescott JT, Kung P, Maiti A. Conductivity of carbon nanotube polymer composites. Appl Phys Lett 2007;90(3):33116(1-3).

[34] Tozzi EJ, Schilling C, Bauhofer W, Klingenberg DJ. Electrical conductivity enhancement in carbon nanotube-polymer composites. Proceedings of the 79th Annual Meeting of the Society of Rheology October 2007, Salt Lake City, Utah, USA.

[35] Switzer LH, Klingenberg DJ. Flocculation in simulations of sheared fiber suspensions. Int $J$ Multiphas Flow 2004;30(1):67-87.

[36] Martin CA, Sandler JKW, Windle AH, Schwarz M-K, Bauhofer W, Schulte K, Shaffer MSP. Electric field-induced aligned multi-wall carbon nanotube networks in epoxy composites. Polymer 2005;46(3):877-86.

[37] Schwarz M-K, Bauhofer W, Schulte K. Alternating electric field induced agglomeration of carbon black filled resins. Polymer 2002;43(10):3079-82.

[38] Park C, Wilkinson J, Banda S, Ounaies Z, Wise KE, Sauti G, Lillehei PT, Harrison JC. Aligned single-wall carbon nanotube polymer composites using an electric field. J Polymer Sci B 2006;44(12):1751-62.

[39] Smith JG, Connell JW, Delozier DM, Lillehei PT, Watson KA, Lin Y, Zhou B, Sun YP. Space durable polymer/carbon nanotube films for electrostatic charge mitigation. Polymer 2004;45(3):825-36.

[40] Moisala A, Li Q, Kinloch IA, Windle AH. Thermal and electrical conductivity of single- and multiwalled carbon nanotube-epoxy composites. Compos Sci Technol 2006;66(10):1285-8.

[41] Sandler J, Shaffer MSP, Prasse T, Bauhofer W, Schulte K, Windle AH. Development of a dispersion process for carbon nanotubes in an epoxy matrix and the resulting electrical properties. Polymer 1999;40(21):5967-71.

[42] Gojny FH, Wichmann MHG, Fiedler B, Kinloch IA, Bauhofer W, Windle AH, Schulte K. Evaluation and identification of electrical and thermal conduction mechanisms in carbon nanotube/epoxy composites. Polymer 2006;47(6):2036-45.

[43] Kim YJ, Shin TS, Choi HD, Kwon JH, Chung YC, Yoon HG. Electrical conductivity of chemically modified multiwalled carbon nanotube/epoxy composites. Carbon 2005;43(1):23-30.

[44] Yu AP, Itkis ME, Bekyarova E, Haddon RC. Effect of single-walled carbon nanotube purity on the thermal conductivity of carbon nanotube-based composites. Appl Phys Lett 2006;89(13):133102(13).

[45] Kim B, Lee J, Yu I. Electrical properties of single-wall carbon nanotube and epoxy composites. J Appl Phys 2003;94(10):6724-8.

[46] Barrau S, Demont P, Maraval C, Bernes A, Lacabanne C. Glass transition temperature depression at the percolation threshold in carbon nanotube-epoxy resin and polypyrrole-epoxy resin composites. Macromol Rapid Commun 2005;26(5):390-4.

[47] Brown JM, Anderson DP, Justice RS, Lafdi K, Belfor M, Strong KL, Schaefer DW. Hierarchical morphology of carbon single-walled nanotubes during sonication in an aliphatic diamine. Polymer 2005;46(24):10854-65.

[48] Li J, Ma PC, Chow WS, To CK, Tang BZ, Kim JK. Correlations between percolation threshold, dispersion state, and aspect ratio of carbon nanotubes. Adv Funct Mater 2007;17:3207-15.

[49] Du FM, Guthy C, Kashiwagi T, Fischer JE, Winey KI. An infiltration method for preparing single-wall nanotube/epoxy composites with improved thermal conductivity. J Polym Sci B 2006;44(10):1513-9.

[50] Barrau S, Demont P, Peigney A, Laurent C, Lacabanne C. DC and AC conductivity of carbon nanotubes-polyepoxy composites. Macromolecules 2003;36:5187-94.

[51] Liu L, Matitsine S, Gan YB, Chen LF, Kong LB, Rozanov KN. Frequency dependence of effective permittivity of carbon nanotube composites. J Appl Phys 2007;101(9):94106(1-7). 
[52] Yuen SM, Ma CCM, Wu HH, Kuan HC, Chen WJ, Liao SH, Hsu CW, Wu HL. Preparation and thermal, electrical, and morphological properties of multiwalled carbon nanotube and epoxy composites. J Appl Polym Sci 2007;103(2):1272-8.

[53] Allaoui A, Bai S, Cheng HM, Bai JB. Mechanical and electrical properties of a MWNT/epoxy composite. Compos Sci Techn 2002;62(15):1993-8.

[54] Cui S, Canet R, Derre A, Couzi M, Delhaes P. Characterization of multiwall carbon nanotubes and influence of surfactant in the nanocomposite processing. Carbon 2003;41(4):797-809.

[55] Pecastaings G,Delhaes P, Derre A, Saadaoui H, Carmona F, Cui S. Role of interfacial effects in carbon nanotube/epoxy nanocomposite behavior. J Nanosci Nanotechnol 2004;4(7):838-43.

[56] Wichmann MHG, Sumfleth J, Fiedler B, Gojny FH, Schulte K. Multiwall carbon nanotube/epoxy composites produced by a masterbatch process. Mech Comp Mat 2006;42(5):395-406.

[57] Wang T, Lei CH, Dalton AB, Creton C, Lin Y, Fernando KAS, Sun YP, Manea M, Asua JM, Keddie JL. Waterborne, nanocomposite pressure-sensitive adhesives with high tack energy, optical transparency, and electrical conductivity. Adv Mater 2006;18(20):2730-4.

[58] Musumeci AW, Silva GG, Liu JW, Martens WN, Waclawik ER. Structure and conductivity of multiwalled carbon nanotube/poly(3-hexylthiophene) composite films. Polymer 2007;48(6):1667-78.

[59] Kymakis E, Amaratunga GAJ. Electrical properties of single-wall carbon nanotube-polymer composite films. J Appl Phys 2006;99(8):84302.

[60] Kodgire PV, Bhattacharyya AR, Bose S, Gupta N, Kulkarni AR, Misra A. Control of multiwall carbon nanotubes dispersion in polyamide6 matrix: an assessment through electrical conductivity. Chem Phys Lett 2006;432(4-6):480-5.

[61] Meincke O, Kaempfer D, Weickmann H, Friedrich C, Vathauer M, Warth H. Mechanical properties and electrical conductivity of carbon-nanotube filled polyamide- 6 and its blends with acrylonitrile/butadiene/styrene. Polymer 2004;45(3):739-48.

[62] Konyushenko EN, Stejskal J, Trchova M, Hradil J, Kovarova J, Prokes J, Cieslar M, Hwang JY, Chen $\mathrm{KH}$, Sapurina I. Multi-wall carbon nanotubes coated with polyaniline. Polymer 2006;47(16):5715-23.

[63] Yoshino K, Kajii H, Araki H, Sonoda T, Take H, Lee S. Electrical and optical properties of conducting polymer-fullerene and conducting polymer-carbon nanotube composites. Full Sci Technol 1999;7(4):695-711.

[64] Nogales A, Broza G, Roslaniec Z, Schulte K, Sics I, Hsiao BS, Sanz A, Garcia-Gutierrez MC, Rueda DR, Domingo C, Ezquerra TA. Low percolation threshold in nanocomposites based on oxidized single wall carbon nanotubes and poly(butylene terephthalate). Macromolecules 2004;37(20):7669-72.

[65] Ramasubramaniam R, Chen J, Liu H. Homogeneous carbon nanotube/polymer composites for electrical applications. Appl Phys Lett 2003;83(14):2928-30.

[66] Pötschke P, Hornbostel B, Roth S, Vohrer U, Dudkin SM, Alig I. Purification and percolation unexpected phenomena in nanotube polymer composites. AIP conference proceedings volume 786: electronic properties of novel nanostructures, Kirchberg, Tirol, Austria, 2005. p. 596-601.

[67] Hornbostel B, Pötschke P, Kotz J, Roth S. Single-walled carbon nanotubes/polycarbonate composites: basic electrical and mechanical properties. Phys Stat Sol B 2006;243(13):3445-51.

[68] Pötschke P, Abdel-Goad M, Alig I, Dudkin S, Lellinger D. Rheological and dielectrical characterization of melt mixed polycarbonate-multiwalled carbon nanotube composites. Polymer 2004;45(26):8863-70.

[69] Pötschke P, Dudkin SM, Alig I. Dielectric spectroscopy on melt processed polycarbonate multiwalled carbon nanotube composites. Polymer 2003;44(17):5023-30.

[70] Chen L, Pang XJ, Yu ZL. Study on polycarbonate/multi-walled carbon nanotubes composite produced by melt processing. Mater Sci Eng A 2007;457(1-2):287-91.

[71] Pötschke P, Fornes TD, Paul DR. Rheological behavior of multiwalled carbon nanotube/polycarbonate composites. Polymer 2002;43(11):3247-55.

[72] Mitchell CA, Krishnamoorti R. Dispersion of single-walled carbon nanotubes in poly(epsiloncaprolactone). Macromolecules 2007;40(5):1538-45. 
[73] Saeed K, Park SY. Preparation and properties of multiwalled carbon nanotube/polycaprolactone nanocomposites. J Appl Polym Sci 2007;104(3):1957-63.

[74] Mierczynska A, Mayne-L'Hermite M, Boiteux G. Electrical and mechanical properties of carbon nanotube/ultrahigh-molecular-weight polyethylene composites prepared by a filler prelocalization method. J Appl Polym Sci 2007;105(1):158-68.

[75] Lisunova MO, Mamunya YP, Lebovka NI, Melezhyk AV. Percolation behaviour of ultrahigh molecular weight polyethylene/multi-walled carbon nanotubes composites. Europ Polym J 2007;43(3):949-58.

[76] Gorrasi G, Sarno M, Di Bartolomeo A, Sannino D, Ciambelli P, Vittoria V. Incorporation of carbon nanotubes into polyethylene by high energy ball milling: Morphology and physical properties. $J$ Polym Sci B 2007;45(5):597-606.

[77] Zhang QH, Rastogi S, Chen DJ, Lippits D, Lemstra PJ. Low percolation threshold in single-walled carbon nanotube/high density polyethylene composites prepared by melt processing technique. Carbon 2006;44(4):778-85.

[78] McNally T, Pötschke P, Halley P, Murphy M, Martin D, Bell SEJ, Brennan GP, Bein D, Lemoine P, Quinn JP. Polyethylene multiwalled carbon nanotube composites. Polymer 2005;46(19):8222-32.

[79] Zhao D, Lei Q, Qin C, Bai X. Melt process and performance of multi-walled carbon nanotubes reinforced LDPE composites. Pigment Resin Technol 2006;35(6):341-5.

[80] McCullen SD, Stevens DR, Roberts WA, Ojha SS, Clarke LI, Gorga RE. Morphological, electrical, and mechanical characterization of electrospun nanofiber mats containing multiwalled carbon nanotubes. Macromolecules 2007;40(4):997-1003.

[81] Awasthi K, Awasthi S, Srivastava A, Kamalakaran R, Talapatra S, Ajayan PM, Srivastava ON. Synthesis and characterization of carbon nanotube-polyethylene oxide composites. Nanotechnology 2006;17(21):5417-22.

[82] K AA, Agarwal US, Joseph R. Carbon nanotubes-reinforced PET nanocomposite by meltcompounding. J Appl Polym Sci 2007;104(5):3090-5.

[83] Hu GJ, Zhao CG, Zhang SM, Yang MS, Wang ZG. Low percolation thresholds of electrical conductivity and rheology in poly(ethylene terephthalate) through the networks of multi-walled carbon nanotubes. Polymer 2006;47(1):480-8.

[84] Lanticse LJ, Tanabe Y, Matsui K, Kaburagi Y, Suda K, Hoteida M, Endo M, Yasuda E. Shearinduced preferential alignment of carbon nanotubes resulted in anisotropic electrical conductivity of polymer composites. Carbon 2006;44(14):3078-86.

[85] Ounaies Z, Park C, Wise KE, Siochi EJ, Harrison JS. Electrical properties of single wall carbon nanotube reinforced polyimide composites. Compos Sci Technol 2003;63(11):1637-46.

[86] Jiang XW, Bin YZ, Matsuo M. Electrical and mechanical properties of polyimide-carbon nanotubes composites fabricated by in situ polymerization. Polymer 2005;46(18):7418-24.

[87] Zhu BK, Xie SH, Xu ZK, Xu YY. Preparation and properties of the polyimide/multi-walled carbon nanotubes (MWNTs) nanocomposites. Compos Sci Technol 2006;66(3-4):548-54.

[88] Schmidt RH, Kinloch IA, Burgess AN, Windle AH. The effect of aggregation on the electrical conductivity of spin-coated polymer/carbon nanotube composite films. Langmuir 2007;23(10):570712.

[89] Chen H, Muthuraman H, Stokes P, Zou JH, Liu X, Wang JH, Huo Q, Khondaker SI, Zhai L. Dispersion of carbon nanotubes and polymer nanocomposite fabrication using trifluoroacetic acid as a co-solvent. Nanotechnology 2007;18(41):415606(1-9).

[90] Benoit JM, Corraze B, Lefrant S, Blau WJ, Bernier P, Chauvet O. Transport properties of PMMAcarbon nanotubes composites. Synth Met 2001;121(1-3):1215-6.

[91] Dai JF, Wang Q, Li WX, Wei ZQ, Xu GJ. Properties of well aligned SWNT modified poly (methyl methacrylate) nanocomposites. Mater Lett 2007;61(1):27-9.

[92] Regev O, EIKati PNB, Loos J, Koning CE. Preparation of conductive nanotube-polymer composites using latex technology. Adv Mater 2004;16(3):248-51. 
[93] Du FM, Fischer JE, Winey KI. Coagulation method for preparing single-walled carbon nanotube/poly(methyl methacrylate) composites and their modulus, electrical conductivity, and thermal stability. J Polym Sci B 2003;41(24):3333-8.

[94] Dettlaff-Weghkowska U, Kaempgen M, Hornbostel B, Skakalova V, Wang JP, Liang JD, Roth S. Conducting and transparent SWNT/polymer composites. Phys Stat Sol B 2006;243(13):3440-4.

[95] Kilbride BE, Coleman JN, Fraysse J, Fournet P, Cadek M, Drury A, Hutzler S, Roth S, Blau WJ. Experimental observation of scaling laws for alternating current and direct current conductivity in polymer-carbon nanotube composite thin films. J Appl Phys 2002;92(7):4024-30.

[96] Curran SA, Ajayan PM, Blau WJ, Carroll DL, Coleman JN, Dalton AB, Davey AP, Drury A, McCarthy B, Maier S, Strevens A. A composite from poly(m-phenylenevinyleneco-2,5-dioctoxy-pphenylenevinylene) and carbon nanotubes: a novel material for molecular optoelectronics. Adv Mater 1998;10(14):1091-3.

[97] Andrews $R$, Jacques $D$, Minot $M$, Rantell $T$. Fabrication of carbon multiwall nanotube/polymer composites by shear mixing. Macromol Mater Eng 2002;287(6):395-403.

[98] Kharchenko SB, Douglas JF, Obrzut J, Grulke EA, Migler KB. Flow-induced properties of nanotubefilled polymer materials. Nat Mater 2004;3(8):564-8.

[99] Tjong SC, Liang GD, Bao SP. Electrical behavior of polypropylene/multiwalled carbon nanotube nanocomposites with low percolation threshold. Scripta Mater 2007;57(6);461-4.

[100] Seo MK, Park SJ. Electrical resistivity and rheological behaviors of carbon nanotubes-filled polypropylene composites. Chem Phys Lett 2004;395(1-3):44-8.

[101] Gorrasi G, Romeo V, Sannino D, Sarno M, Ciambelli P, Vittoria V, De Vivo B, Tucci V. Carbon nanotube induced structural and physical property transitions of syndiotactic polypropylene. Nanotechnology 2007;18(27):275703(1-11).

[102] Aarab H, Baitoul M, Wery J, Almairac R, Lefrant S, Faulques E, Duvail JL, Hamedoun M. Electrical and optical properties of PPV and single-walled carbon nanotubes composite films. Synth Met 2005;155(1):63-7.

[103] Sluzarenko N, Heurtefeu B, Maugey M, Zakri C, Poulin P, Lecommandoux S. Diblock copolymer stabilization of multi-wall carbon nanotubes in organic solvents and their use in composites. Carbon 2006;44(15):3207-12.

[104] Chang TE, Kisliuk A, Rhodes SM, Brittain WJ, Sokolov AP. Conductivity and mechanical properties of well-dispersed single-wall carbon nanotube/polystyrene composite. Polymer 2006;47(22):7740-6.

[105] Kim ST, Choi HJ, Hong SM. Bulk polymerized polystyrene in the presence of multiwalled carbon nanotubes. Coll Polym Sci 2007;285(5):593-8.

[106] Poa CH, Silva SRP, Watts PCP, Hsu WK, Kroto HW, Walton DRM. Field emission from nonaligned carbon nanotubes embedded in a polystyrene matrix. Appl Phys Lett 2002;80(17):3189-91.

[107] Ha MLP, Grady BP, Lolli G, Resasco DE, Ford WT. Composites of single-walled carbon nanotubes and styrene-isoprene copolymer latices. Macromol Chem Phys 2007;208(5):446-56.

[108] Dalmas F, Cavaille J-Y, Gauthier C, Chazeau L, Dendievel R. Viscoelastic behavior and electrical properties of flexible nanofiber filled polymer nanocomposites. Influence of processing conditions. Compos Sci Technol 2007;67(5):829-39.

[109] Antonucci V, Faiella G, Giordano M, Nicolais L, Pepe G. Electrical properties of single walled carbon nanotube reinforced polystyrene composites. Macromol Symp 2007;247:172-81.

[110] Dufresne A, Paillet M, Putaux J L, Canet R, Carmona F, Delhaes P, Cui S. Processing and characterization of carbon nanotube/poly(styrene-co-butyl acrylate) nanocomposites. J Mater Sci 2002;37(18):3915-23.

[111] Kim YJ, An KJ, Suh KS, Choi HD, Kwon JH, Chung YC, Kim WN, Lee AK, Choi JI, Yoon HG. Hybridization of oxidized MWNT and silver powder in polyurethane matrix for electromagnetic interference shielding application. IEEE Trans Electromag Compatibility 2005;47(4):872-9.

[112] Wang G, Tan ZK, Liu XQ, Chawda S, Koo JS, Samuilov V, Dudley M. Conducting MWNT/poly(vinyl acetate) composite nanofibres by electrospinning. Nanotechnology 2006;17(23):5829-35.

[113] Shaffer MSP, Windle AH. Fabrication and characterization of carbon nanotube/poly(vinyl alcohol) composites. Adv Mater 1999;11(11):937-41. 
[114] Grunlan JC, Mehrabi AR, Bannon MV, Bahr JL. Water-based single-walled-nanotube-filled polymer composite with an exceptionally low percolation threshold. Adv Mater 2004;16(2):150-3.

[115] Mamunya Y, Boudenne A, Lebovka N, Ibos L, Candau Y, Lisunova M. Electrical and Thermophysical behaviour of PVC-MWCNT Nanocomposites. Compos Sci Technol 2008;68(9):1981-8.

[116] Seoul C, Kim YT, Baek CK. Electrospinning of poly(vinylidene fluoride)/dimethylformamide solutions with carbon nanotubes. J Polym Sci B 2003;41(13):1572-7.

[117] Wang L, Dang ZM. Carbon nanotube composites with high dielectric constant at low percolation threshold. Appl Phys Lett 2005;87(4):42903(1-3).

[118] Bian CX, Xu XC, Yang GG, Zhao Y, Jin SS, Wang HM, Tang GQ. Studies on conductive properties and mechanism of composites-sulfonated polyphenylacetylene/multiwalled carbon nanotubes. Acta Chimica Sinica 2007;65(6):525-31.

[119] Kimura T, Ago H, Tobita M, Ohshima S, Kyotani M, Yumura M. Polymer composites of carbon nanotubes aligned by a magnetic field. Adv Mater 2002;14(19):1380-3.

[120] Gryshchuk O, Karger-Kocsis J, Thomann R, Konya Z, Kiricsi I. Multiwall carbon nanotube modified vinylester and vinylester-based hybrid resins. Compos A 2006;37(9):1252-9.

[121] Jiang MJ, Dang ZM, Xu HP. Giant dielectric constant and resistance-pressure sensitivity in carbon nanotubes/rubber nanocomposites with low percolation threshold. Appl Phys Lett 2007;90(4):42914(1-3).

Table 1. Summary of the experimental parameters of all reviewed publications, arranged alphabetically with respect to the polymer matrices, the data for a given polymer arranged with increasing percolation threshold.

Acronyms: ADA (aminododecanoic acid), AHA (aminohexanoic acid), AIBN (azoisobutyronitrile), APTS (aminopropyltriethoxy silane), ASTAA (alkoxysilane terminated amide acid), BKC (benzalkonium chloride), e (entangled), GA (gum arabic), MEK (methyl ethyl ketone), ne (non-entangled), OP (polyoxyethylene octyl phenyl ether), P3HT (poly 3-hexylthiophene), P3OT (poly 3-octylthiophene), PA-6 (polyamide-6), PANI (polyaniline), PAT (polyhexadecyl thiophene), PBT (polybutylene terephthalate), $P(B u A)$ (polybutyl acrylate), PC (polycarbonate), PCL (polycaprolactone), PE (polyethylene), PEE (polyphenylene ethynylene), PEO (polyethylene oxide), PET (polyethylene terephthalate), PFA (polyfurfuryl alcohol), PI (polyimide), PMMA (polymethyl methacrylate), PmPV (poly-m-phenylenevinylene), PP (polypropylene), PPV (polyparaphenylene vinylene), PS (polystyrene), PU (polyurethane), PVA (polyvinyl acetate), PVC (polyvinyl chloride), PVDF (polyvinylidene difluoride), SDBS (sodium dodecylbenzenesulfonate), SDS (sodium dodecyl sulfate), SPPA (sulfonated polyphenylacetylene), UPR (unsaturated polyester resin), VE (vinylester), VMQ (methylvinyl silicone rubber). 


\begin{tabular}{|c|c|c|c|c|c|c|c|c|c|c|}
\hline Matrix & Filler & State & Treatment & $d / l$ & Solution & Dispersion & $\Phi c$ [wt \%] & $\mathbf{t}$ & $\sigma \max [S / m]$ & Ref. \\
\hline ASTAA & $\begin{array}{l}\text { SWCNT (HiPcoß), } \\
\text { Rice Univ. }\end{array}$ & $\mathrm{e}$ & $\mathrm{HCl}$ & - & C4H9NO & sonicated, stirred & 0.035 & - & $\begin{array}{c}1 \mathrm{E}-7 \\
0.08 \text { wt\% }\end{array}$ & [39] \\
\hline Epoxy & MWCNT (CVD) & ne & - & 200 & - & heat sheared & 0.0021 & 1.8 & $\begin{array}{c}\mathrm{E}-3 \\
0.01 \text { wt\% }\end{array}$ & [13] \\
\hline Epoxy & MWCNT (CVD) & ne & - & 340 & - & heat sheared & 0.0025 & 1.2 & $\begin{array}{c}2 E+0 \\
@ 1 w t \%\end{array}$ & {$[6]$} \\
\hline Epoxy & MWCNT (CVD) & ne & - & 1000 & - & heat sheared & 0.0025 & - & $\begin{array}{c}4 \mathrm{E}-1 \\
@ 0.5 \text { wt\% }\end{array}$ & [40] \\
\hline Epoxy & MWCNT (CVD) & ne & - & 860 & - & heat sheared & 0.0039 & 1.7 & $\begin{array}{c}2 \mathrm{E}-4 \\
0.01 \text { wt\% } \\
\end{array}$ & [13] \\
\hline Epoxy & $\begin{array}{l}\text { SWCNT (Laser), } \\
\text { Rice Univ. }\end{array}$ & e & purified & 400 & $\mathrm{C} 6 \mathrm{H} 8 \mathrm{O}$ & $\begin{array}{c}\text { sonicated, } \\
\text { cured without }\end{array}$ & 0.005 & 2.7 & $\begin{array}{ll}2 \mathrm{E}-2 \\
0.1 \mathrm{wt} \%\end{array}$ & [7] \\
\hline Epoxy & $\begin{array}{l}\text { SWCNT (HiPcoß), } \\
\text { Carbon Nanotech. }\end{array}$ & e & purified & 150 & $\mathrm{C} 6 \mathrm{H} 8 \mathrm{O}$ & $\begin{array}{c}\text { sonicated, } \\
\text { cured without }\end{array}$ & 0.009 & 3.1 & $\begin{array}{c}1 \mathrm{E}-5 \\
0.04 \text { wt\% } \\
\end{array}$ & [7] \\
\hline Epoxy & $\begin{array}{l}\text { SWCNT (Laser), } \\
\text { Rice Univ. }\end{array}$ & e & purified & 400 & $\mathrm{C} 6 \mathrm{H} 8 \mathrm{O}$ & sonicated, cured with & 0.01 & 1.6 & $\begin{array}{l}5 \mathrm{E}-3 \\
@ 0.4 \text { wt\% }\end{array}$ & [7] \\
\hline Epoxy & $\begin{array}{c}\text { MWCNT (CVD), } \\
\text { Nanocyl }\end{array}$ & e & - & 1000 & - & $\begin{array}{c}\text { stirred, heat sheared } \\
\text { (slowly) }\end{array}$ & 0.011 & 1.7 & $\begin{array}{c}4 \mathrm{E}-1 \\
@ 1 w t \%\end{array}$ & [8] \\
\hline Epoxy & $\begin{array}{l}\text { SWCNT (HiPcoß), } \\
\text { Carbon Nanotech. }\end{array}$ & e & purified & 150 & $\mathrm{C} 6 \mathrm{H} 8 \mathrm{O}$ & sonicated, cured with & 0.023 & 3.2 & $\begin{array}{l}2 E-4 \\
0.2 \text { wt\% }\end{array}$ & {$[7]$} \\
\hline Epoxy & $\begin{array}{c}\text { MWCNT (CVD), } \\
\text { Nanocyl }\end{array}$ & e & - & 1000 & - & $\begin{array}{l}\text { stirred, heat sheared } \\
\text { (medium) }\end{array}$ & 0.024 & 1.7 & $\begin{array}{c}3 \mathrm{E}-1 \\
@ 1 \mathrm{wt} \%\end{array}$ & [8] \\
\hline Epoxy & $\begin{array}{l}\text { MWCNT (CVD), } \\
\text { Hyperion Catalysis }\end{array}$ & e & - & 100 & $\mathrm{C} 2 \mathrm{H} 6 \mathrm{O}$ & sonicated, stirred & 0.03 & - & $\begin{array}{c}5 \mathrm{E}-1 \\
0.15 w t \%\end{array}$ & [41] \\
\hline Epoxy & $\begin{array}{l}\text { MWCNT (CVD), } \\
\text { Nanocyl }\end{array}$ & e & & 1000 & - & calendered, stirred & 0.03 & - & $\begin{array}{c}1 \mathrm{E}-2 \\
0.3 w t \%\end{array}$ & [42] \\
\hline Epoxy & $\begin{array}{l}\text { MWCNT (CVD), } \\
\text { Iljin Nanotech. }\end{array}$ & e & $\begin{array}{c}\text { HNO3, centrifuged, } \\
\text { C3H6O }\end{array}$ & 1000 & OP & sonicated & 0.034 & 1.7 & $\begin{array}{c}1 \mathrm{E}-1 \\
@ 2 \mathrm{wt} \%\end{array}$ & [43] \\
\hline Epoxy & $\begin{array}{c}\text { SWCNT (Arc), } \\
\text { Carbon Solutions Inc. }\end{array}$ & - & - & - & $\mathrm{C} 3 \mathrm{H} 6 \mathrm{O}$ & sonicated, stirred & 0.04 & 1.7 & $\begin{array}{c}1 \mathrm{E}+1 \\
@ 4 \mathrm{wt} \%\end{array}$ & [44] \\
\hline Epoxy & $\begin{array}{l}\text { SWCNT (CVD), } \\
\text { Thomas Swan }\end{array}$ & - & - & 1000 & - & calendered, stirred & 0.04 & - & $\begin{array}{c}1 \mathrm{E}-3 \\
0.4 \text { wt\% }\end{array}$ & [42] \\
\hline Epoxy & $\begin{array}{l}\text { MWCNT (CVD), } \\
\text { Iljin Nanotech. }\end{array}$ & e & $\begin{array}{c}\mathrm{H} 2 \mathrm{O} 2 / \mathrm{NH} 4 \mathrm{OH}, \\
\text { centrifuged, } \mathrm{C} 3 \mathrm{H} 6 \mathrm{O}\end{array}$ & 1000 & OP & sonicated & 0.042 & 1.8 & $\begin{array}{c}1 \mathrm{E}+0 \\
@ 2 w t \%\end{array}$ & [43] \\
\hline
\end{tabular}




\begin{tabular}{|c|c|c|c|c|c|c|c|c|c|c|}
\hline Epoxy & $\begin{array}{l}\text { SWCNT (CVD), } \\
\text { Thomas Swan }\end{array}$ & - & - & - & $\begin{array}{c}\mathrm{C} 2 \mathrm{H} 6 \mathrm{O} \\
\mathrm{NaOH}\end{array}$ & $\begin{array}{c}\text { sonicated, } \\
\text { heat sheared }\end{array}$ & 0.05 & - & $\begin{array}{c}3 \mathrm{E}-2 \\
0.5 \mathrm{wt} \%\end{array}$ & [40] \\
\hline Epoxy & $\begin{array}{l}\text { SWCNT (Arc), } \\
\text { Iljin Nanotech. }\end{array}$ & e & $\begin{array}{l}\text { thermal oxidation, } \\
\text { chemical treatment }\end{array}$ & 5000 & $\mathrm{C} 2 \mathrm{H} 6 \mathrm{O}$ & $\begin{array}{c}\text { sonicated, } \\
\text { vacuum pumped }\end{array}$ & 0.074 & 1.3 & $\begin{array}{c}1 \mathrm{E}-3 \\
0.2 \mathrm{wt} \%\end{array}$ & [45] \\
\hline Epoxy & $\begin{array}{l}\text { MWCNT (CVD), } \\
\text { Nanocyl }\end{array}$ & e & - & 1000 & - & $\begin{array}{l}\text { stirred, heat sheared } \\
\text { (fast) }\end{array}$ & 0.08 & 2.0 & $\begin{array}{l}4 \mathrm{E}-2 \\
0.6 \mathrm{wt} \%\end{array}$ & [8] \\
\hline Epoxy & SWCNT (CVD) & - & $\mathrm{HCl}$ & - & $\mathrm{H} 2 \mathrm{O}$ & stirred & 0.08 & - & $\begin{array}{l}2 E-2 \\
0.4 \text { wt\% }\end{array}$ & [46] \\
\hline Epoxy & $\begin{array}{l}\text { SWCNT (HiPcoß), } \\
\text { Rice Univ. }\end{array}$ & e & $\mathrm{HCl}$ & - & - & sonicated & 0.1 & - & - & [47] \\
\hline Epoxy & $\begin{array}{l}\text { MWCNT (CVD), } \\
\text { Iljin Nanotech. }\end{array}$ & e & - & 1000 & $\mathrm{C} 3 \mathrm{H} 6 \mathrm{O}$ & sonicated & 0.1 & - & $\begin{array}{c}2 \mathrm{E}-1 \\
@ 1 \mathrm{wt} \%\end{array}$ & [48] \\
\hline Epoxy & $\begin{array}{c}\text { MWCNT, } \\
\text { Nano Carbon Tech. }\end{array}$ & - & - & 100 & - & stirred & 0.1 & 1.8 & $\begin{array}{c}1 \mathrm{E}-2 \\
0.12 \text { wt\% }\end{array}$ & [29] \\
\hline Epoxy & $\begin{array}{c}\text { DWCNT (CVD), } \\
\text { Nanocyl }\end{array}$ & e & - & 1000 & - & calendered, stirred & 0.15 & - & $\begin{array}{c}1 \mathrm{E}-2 \\
0.6 \text { wt\% }\end{array}$ & [42] \\
\hline Epoxy & $\begin{array}{l}\text { SWCNT (CVD), } \\
\text { Thomas Swan }\end{array}$ & - & - & - & - & $\begin{array}{c}\text { ball milled, } \\
\text { heat sheared }\end{array}$ & 0.23 & - & $\begin{array}{c}1 \mathrm{E}-3 \\
0.5 \text { wt\% }\end{array}$ & [40] \\
\hline Epoxy & $\begin{array}{l}\text { MWCNT (CVD), } \\
\text { Nanocyl }\end{array}$ & e & $\mathrm{NH}$-functionalized & - & - & calendered, stirred & 0.25 & - & $\begin{array}{ll} & 5 \mathrm{E}-4 \\
0.4 \mathrm{wt} \%\end{array}$ & [42] \\
\hline Epoxy & $\begin{array}{l}\text { DWCNT (CVD), } \\
\text { Nanocyl }\end{array}$ & e & NH2-functionalized & - & - & calendered, stirred & 0.25 & - & $\begin{array}{c}3 E-4 \\
@ 0.6 \text { wt } \% \\
\end{array}$ & [42] \\
\hline Epoxy & $\begin{array}{l}\text { MWCNT (CVD), } \\
\text { Iljin Nanotech. }\end{array}$ & $\mathrm{e}$ & UV/O3 & 1000 & $\mathrm{C} 3 \mathrm{H} 6 \mathrm{O}$ & sonicated & 0.27 & - & $\begin{array}{c}2 \mathrm{E}-2 \\
@ 1 \mathrm{wt} \%\end{array}$ & [48] \\
\hline Epoxy & $\begin{array}{l}\text { SWCNT (HiPcoß), } \\
\text { Carbon Nanotech. }\end{array}$ & e & - & - & - & $\begin{array}{l}\text { PMMA removal, } \\
\text { Epoxy infiltration }\end{array}$ & 0.3 & - & $\begin{array}{c}5 \mathrm{E}-1 \\
@ 3 \mathrm{wt} \%\end{array}$ & [49] \\
\hline Epoxy & SWCNT (CVD) & - & - & - & $\mathrm{C} 2 \mathrm{H} 6 \mathrm{O}$ & sonicated, stirred & 0.3 & 1.4 & $\begin{array}{c}1 \mathrm{E}-2 \\
\text { @ } 2.5 \text { wt\% }\end{array}$ & [50] \\
\hline Epoxy & $\begin{array}{l}\text { MWCNT (CVD), } \\
\text { Iljin Nanotech. }\end{array}$ & e & - & 1000 & & stirred & 0.4 & - & $\begin{array}{c}2 \mathrm{E}-2 \\
@ 1 \mathrm{wt} \%\end{array}$ & [48] \\
\hline Epoxy & MWCNT (CVD) & e & - & 400 & $\mathrm{CH} 4 \mathrm{O}$ & stirred & 0.5 & - & $\begin{array}{c}5 E+0 \\
@ 3 w t \%\end{array}$ & [12] \\
\hline Epoxy & $\begin{array}{c}\text { SWCNT (Arc) } \\
\text { Aldrich }\end{array}$ & e & - & 1000 & - & manually mixed & 0.6 & - & $\begin{array}{c}1 \mathrm{E}-2 \\
@ 14 \mathrm{wt} \% \\
\end{array}$ & [51] \\
\hline Epoxy & $\begin{array}{c}\text { MWCNT (CVD), } \\
\text { Shenzhen Nanotech. }\end{array}$ & e & - & 100 & $\mathrm{C} 3 \mathrm{H} 6 \mathrm{O}$ & stirred & 0.6 & 2.9 & $\begin{array}{c}5 \mathrm{E}-3 \\
\text { @ } 10 \mathrm{wt} \%\end{array}$ & [52] \\
\hline
\end{tabular}




\begin{tabular}{|c|c|c|c|c|c|c|c|c|c|c|}
\hline Epoxy & MWCNT (CVD) & - & - & $>500$ & $\mathrm{CH} 4 \mathrm{O}$ & stirred, hot pressed & 0.7 & - & $\begin{array}{c}5 E+0 \\
@ 4 w t \% \\
\end{array}$ & [53] \\
\hline Epoxy & $\begin{array}{c}\text { SWCNT (Arc), } \\
\text { Carbon Solutions Inc. }\end{array}$ & $\mathrm{e}$ & HNO3 & - & $\mathrm{C} 3 \mathrm{H} 6 \mathrm{O}$ & sonicated, stirred & 1 & 2.4 & $\begin{array}{c}1 \mathrm{E}-1 \\
\text { @ } 7.5 \text { wt\% }\end{array}$ & [44] \\
\hline Epoxy & MWCNT (CVD) & $\mathrm{e}$ & - & 80 & $\mathrm{CH} 4 \mathrm{O}$ & stirred, filtrated & 1.5 & - & $\begin{array}{c}1 \mathrm{E}-3 \\
@ 3 \mathrm{wt} \% \\
\end{array}$ & [12] \\
\hline Epoxy & MWCNT (CVD) & - & HNO3 & 20 & $\mathrm{C} 3 \mathrm{H} 6 \mathrm{O}$ & sonicated, stirred & 3.5 & - & $\begin{array}{c}1 \mathrm{E}-5 \\
@ 8 w t \% \\
\end{array}$ & [54] \\
\hline Epoxy & $\begin{array}{l}\text { MWCNT (Arc), } \\
\text { Aldrich }\end{array}$ & $\mathrm{e}$ & - & 100 & - & manually mixed & 4 & - & $\begin{array}{l}1 \mathrm{E}-3 \\
@ 16 \text { wt\% }\end{array}$ & [51] \\
\hline Epoxy & MWCNT (CVD) & - & - & $>20$ & $\mathrm{C} 3 \mathrm{H} 6 \mathrm{O}$ & sonicated, stirred & 5 & - & $\begin{array}{c}2 E-5 \\
\text { @ } 20 \text { wt\% }\end{array}$ & [55] \\
\hline Epoxy & MWCNT (CVD) & - & HNO3 & 20 & $\begin{array}{l}\text { C3H6O, } \\
\text { Tergitol }\end{array}$ & sonicated, stirred & 5 & - & $\begin{array}{c}1 \mathrm{E}-5 \\
@ 8 \mathrm{wt} \% \\
\end{array}$ & [54] \\
\hline Epoxy & $\begin{array}{l}\text { MWCNT (CVD), } \\
\text { Arkema }\end{array}$ & e & - & - & - & $\begin{array}{c}\text { calendered, } \\
\text { vacuum stirred }\end{array}$ & $<0.5$ & - & $\begin{array}{c}3 E-2 \\
@ 2 \text { wt } \%\end{array}$ & [56] \\
\hline $\begin{array}{l}\mathrm{P}(\mathrm{BuA}) \\
\text { latex }\end{array}$ & SWCNT (Arc) & e & PVA-functionalized & - & $\mathrm{H} 2 \mathrm{O}$ & sonicated & 0.27 & - & $\begin{array}{c}5 E+0 \\
@ 1 w t \%\end{array}$ & [57] \\
\hline $\mathrm{P} 3 \mathrm{HT}$ & $\begin{array}{c}\text { MWCNT (CVD), } \\
\text { Nanocyl }\end{array}$ & $\mathrm{e}$ & - & $<100$ & $\mathrm{CHCl} 3$ & $\begin{array}{c}\text { sonicated, } \mathrm{CH} 4 \mathrm{O} \\
\text { (coagulation) }\end{array}$ & 0.1 & 1.7 & $\begin{array}{c}5 \mathrm{E}-1 \\
@ 20 \text { wt\% }\end{array}$ & [58] \\
\hline Р3OT & $\begin{array}{l}\text { SWCNT (Arc), } \\
\text { CarboLex }\end{array}$ & e & $\mathrm{HCl}$, centrifuged & 100 & $\mathrm{CHCl} 3$ & $\begin{array}{l}\text { sonicated, } \\
\text { spincoated }\end{array}$ & 4 & 2.0 & $\begin{array}{c}5 \mathrm{E}-2 \\
\text { @ } 35 \text { wt\% } \\
\end{array}$ & [59] \\
\hline P3OT & $\begin{array}{l}\text { SWCNT (Arc), } \\
\text { CarboLex }\end{array}$ & e & - & 100 & $\mathrm{CHCl} 3$ & $\begin{array}{l}\text { sonicated, } \\
\text { spincoated }\end{array}$ & 11 & 2.0 & $\begin{array}{c}1 \mathrm{E}-3 \\
\text { @ } 35 \mathrm{wt} \% \\
\end{array}$ & [59] \\
\hline PA-6 & $\begin{array}{c}\text { MWCNT (CVD), } \\
\text { Nanocyl }\end{array}$ & $\mathrm{e}$ & - & $\begin{array}{c}< \\
1000\end{array}$ & $\begin{array}{c}\mathrm{H} 2 \mathrm{O}, \\
\mathrm{Na}-\mathrm{AHA}\end{array}$ & $\begin{array}{c}\text { sonicated, dried, } \\
\text { extruded, hot pressed }\end{array}$ & 2.5 & - & $\begin{array}{c}3 E-2 \\
@ 4 w t \%\end{array}$ & [60] \\
\hline PA-6 & $\begin{array}{c}\text { MWCNT (CVD), } \\
\text { Hyperion Catalysis }\end{array}$ & $\mathrm{e}$ & - & - & - & extruded & 7 & - & $\begin{array}{c}1 \mathrm{E}+1 \\
@ 16 \mathrm{wt} \% \\
\end{array}$ & {$[61]$} \\
\hline PANI & $\begin{array}{l}\text { SWCNT (HiPcoß), } \\
\text { Carbon Nanotech. }\end{array}$ & e & - & - & - & sonicated & 0.3 & 2.1 & $\begin{array}{c}\mathrm{E}+3 \\
@ 15 \mathrm{wt} \%\end{array}$ & [18] \\
\hline PANI & $\begin{array}{l}\text { SWCNT (HiPcoß), } \\
\text { Carbon Nanotech. }\end{array}$ & $\mathrm{e}$ & - & - & $\mathrm{C} 8 \mathrm{H} 10$ & sonicated & 0.3 & 2.1 & $\begin{array}{c}3 E+2 \\
@ 20 w t \%\end{array}$ & [18] \\
\hline PANI & $\begin{array}{l}\text { SWCNT (Laser), } \\
\text { Carbon Nanotech. }\end{array}$ & e & - & - & $\mathrm{C} 8 \mathrm{H} 10$ & sonicated & 0.3 & 2.1 & $\begin{array}{c}3 E+2 \\
@ 20 w t \%\end{array}$ & [18] \\
\hline
\end{tabular}


MWCNT,

PANI Conyuan Biochem

500

blended, compressed

4

$1 \mathrm{E}+3$ Technology

\begin{tabular}{|c|c|c|c|c|c|c|c|c|c|c|}
\hline PAT & MWCNT (CVD) & ne & $\mathrm{HNO} 3, \mathrm{CHCl} 3$ & $>200$ & $\begin{array}{l}\text { C6H12, } \\
\text { CHCL3 }\end{array}$ & sonicated & 12 & 2.6 & $\begin{array}{c}5 \mathrm{E}+1 \\
@ 35 \mathrm{wt} \%\end{array}$ & [63] \\
\hline PBT & $\begin{array}{l}\text { SWCNT (HiPco®), } \\
\text { Carbon Nanotech. }\end{array}$ & e & oxidized & - & - & sonicated, extruded & 0.2 & - & $\begin{array}{c}1 \mathrm{E}-8 \\
@ 0.2 \text { wt } \% \\
\end{array}$ & [64] \\
\hline PC & $\begin{array}{l}\text { SWCNT (HiPco®), } \\
\text { Carbon Nanotech. }\end{array}$ & e & PEE-functionalized & - & $\mathrm{CHCl} 3$ & shaken, sonicated & 0.1 & 2.8 & $\begin{array}{c}5 E+2 \\
@ 7 w t \%\end{array}$ & [65] \\
\hline PC & $\begin{array}{l}\text { SWCNT (HiPco®), } \\
\text { Carbon Nanotech. }\end{array}$ & e & - & - & - & extruded & 0.3 & - & $\begin{array}{c}1 \mathrm{E}-1 \\
@ 1 \mathrm{wt} \%\end{array}$ & [66] \\
\hline PC & SWCNT (Arc) & e & - & - & $\begin{array}{l}\mathrm{C} 6 \mathrm{H} 8 \mathrm{O}, \\
\mathrm{CHCl} 3, \\
\mathrm{C} 2 \mathrm{H} 6 \mathrm{O}\end{array}$ & $\begin{array}{l}\text { sonicated, filtrated, } \\
\text { hot pressed }\end{array}$ & 0.5 & - & $\begin{array}{c}3 E+1 \\
@ 17 w t \%\end{array}$ & [67] \\
\hline PC & SWCNT (HiPco®) & e & - & - & $\begin{array}{l}\mathrm{C} 6 \mathrm{H} 8 \mathrm{O}, \\
\mathrm{CHCl} 3, \\
\mathrm{C} 2 \mathrm{H} 6 \mathrm{O}\end{array}$ & $\begin{array}{l}\text { sonicated, filtrated, } \\
\text { hot pressed }\end{array}$ & 0.5 & - & $\begin{array}{c}1 \mathrm{E}+1 \\
@ 1 w t \%\end{array}$ & [67] \\
\hline PC & SWCNT (HiPco®) & e & - & - & - & extruded & 0.5 & - & $\begin{array}{c}1 \mathrm{E}-1 \\
@ 2 \mathrm{wt} \%\end{array}$ & [67] \\
\hline PC & $\begin{array}{l}\text { MWCNT (CVD), } \\
\text { Hyperion Catalysis }\end{array}$ & e & - & 1000 & - & extruded & 1 & 3.8 & $\begin{array}{c}5 \mathrm{E}+0 \\
@ 3 w t \%\end{array}$ & [68] \\
\hline PC & $\begin{array}{l}\text { MWCNT (CVD), } \\
\text { Hyperion Catalysis }\end{array}$ & e & - & $>100$ & - & extruded & 1.44 & 2.1 & $\begin{array}{c}2 \mathrm{E}+0 \\
@ 5 w t \%\end{array}$ & [69] \\
\hline PC & SWCNT (Arc) & e & - & - & - & extruded & 1.9 & - & $\begin{array}{c}1 \mathrm{E}-1 \\
@ 10 \mathrm{wt} \%\end{array}$ & [67] \\
\hline PC & SWCNT (Arc) & e & - & - & $\mathrm{CHCl} 3$ & sonicated, extruded & 1.9 & - & $\begin{array}{c}1 \mathrm{E}-1 \\
@ 4 \mathrm{wt} \%\end{array}$ & [67] \\
\hline PC & SWCNT (Arc) & e & - & - & - & extruded & 2.5 & - & $\begin{array}{c}1 \mathrm{E}-1 \\
@ 7 \mathrm{wt} \%\end{array}$ & [66] \\
\hline PC & MWCNT (CVD) & e & $\mathrm{HCl}$ & 1000 & - & extruded & 5 & - & $\begin{array}{c}1 \mathrm{E}-4 \\
@ 15 \mathrm{wt} \%\end{array}$ & [70] \\
\hline PC & $\begin{array}{c}\text { MWCNT (CVD), } \\
\text { Hyperion Catalysis }\end{array}$ & e & - & $>100$ & - & extruded & $1-2$ & - & $\begin{array}{c}1 \mathrm{E}+1 \\
@ 15 \mathrm{wt} \%\end{array}$ & [71] \\
\hline PC & $\begin{array}{l}\text { SWCNT (HiPco®), } \\
\text { Carbon Nanotech. }\end{array}$ & e & $\begin{array}{c}\text { annealed, } \mathrm{SOCl} 2 \\
\text { centrifuged }\end{array}$ & - & - & extruded & - & - & $\begin{array}{c}1 \mathrm{E}-1 \\
@ 1 \mathrm{wt} \%\end{array}$ & [66] \\
\hline
\end{tabular}




\begin{tabular}{|c|c|c|c|c|c|c|c|c|c|c|}
\hline $\mathrm{PC}$ & SWCNT (Arc) & e & $\begin{array}{c}\text { annealed, SOCl2, } \\
\text { centrifuged }\end{array}$ & - & - & extruded & $>5$ & - & $\begin{array}{c}1 \mathrm{E}-1 \\
@ 7 \mathrm{wt} \%\end{array}$ & {$[66]$} \\
\hline PCL & $\begin{array}{l}\text { SWCNT (HiPco®), } \\
\text { Carbon Nanotech. }\end{array}$ & e & purified & - & $\mathrm{C} 7 \mathrm{H} 8, \mathrm{ADA}$ & sonicated & 0.09 & 1.5 & $\begin{array}{c}1 \mathrm{E}-3 \\
@ 3 \mathrm{wt} \%\end{array}$ & [72] \\
\hline PCL & $\begin{array}{l}\text { MWCNT (CVD), } \\
\text { Iljin Nanotech. }\end{array}$ & e & - & 1000 & - & sonicated, stirred & 1.5 & - & $\begin{array}{c}1 \mathrm{E}+1 \\
@ 7 w t \% \\
\end{array}$ & [73] \\
\hline PCL & $\begin{array}{l}\text { MWCNT (CVD), } \\
\text { Iljin Nanotech. }\end{array}$ & e & HNO3, filtrated & 1000 & - & sonicated, stirred & 4 & - & $\begin{array}{c}1 \mathrm{E}+0 \\
@ 7 \mathrm{wt} \%\end{array}$ & [73] \\
\hline $\begin{array}{c}\text { PE, } \\
\text { UHMW }\end{array}$ & MWCNT (CVD) & ne & - & 100 & $\mathrm{H} 2 \mathrm{O}, \mathrm{SDS}$ & $\begin{array}{l}\text { sonicated, dry mixed, } \\
\text { hot pressed }\end{array}$ & 0.045 & 2.6 & $\begin{array}{c}5 E+1 \\
@ 1 w t \%\end{array}$ & [74] \\
\hline $\begin{array}{c}\text { PE, } \\
\text { UHMW }\end{array}$ & MWCNT (CVD) & - & $\mathrm{NaOH}, \mathrm{HCl}$ & $>100$ & - & stirred, hot pressed & 0.07 & 2.1 & $\begin{array}{c}1 \mathrm{E}-2 \\
@ 0.7 \mathrm{wt} \%\end{array}$ & {$[75]$} \\
\hline $\begin{array}{c}\text { PE, } \\
\text { UHMW }\end{array}$ & $\begin{array}{l}\text { SWCNT (Arc), } \\
\text { CarboLex }\end{array}$ & e & - & - & $\mathrm{C} 6 \mathrm{H} 8 \mathrm{O}$ & $\begin{array}{l}\text { sonicated, dry mixed, } \\
\text { hot pressed }\end{array}$ & 0.09 & 2.3 & $\begin{array}{c}5 \mathrm{E}-2 \\
@ 2 w t \%\end{array}$ & {$[74]$} \\
\hline $\begin{array}{c}\text { PE, } \\
\text { UHMW }\end{array}$ & MWCNT (CVD) & - & $\mathrm{NaOH}, \mathrm{HCl}$ & $>100$ & - & stirred & 0.14 & 1.8 & $\begin{array}{c}1 \mathrm{E}-1 \\
0.7 \mathrm{wt} \% \\
\end{array}$ & {$[75]$} \\
\hline $\begin{array}{c}\text { PE, } \\
\text { UHMW }\end{array}$ & MWCNT (CVD) & ne & - & 100 & $\mathrm{C} 6 \mathrm{H} 8 \mathrm{O}$ & $\begin{array}{l}\text { sonicated, dry mixed, } \\
\text { hot pressed }\end{array}$ & 0.19 & 2.7 & $\begin{array}{c}1 \mathrm{E}+2 \\
@ 1 \mathrm{wt} \% \\
\end{array}$ & {$[74]$} \\
\hline $\begin{array}{c}\text { PE, } \\
\text { UHMW }\end{array}$ & $\begin{array}{l}\text { SWCNT (Arc), } \\
\text { CarboLex }\end{array}$ & $\mathrm{e}$ & - & - & $\mathrm{C} 2 \mathrm{H} 6 \mathrm{O}$ & $\begin{array}{l}\text { sonicated, dry mixed, } \\
\text { hot pressed }\end{array}$ & 0.25 & 2.2 & $\begin{array}{c}5 \mathrm{E}-1 \\
@ 3 \text { wt\% }\end{array}$ & {$[74]$} \\
\hline $\begin{array}{c}\text { PE, } \\
\text { UHMW }\end{array}$ & MWCNT (CVD) & ne & - & 5000 & - & dry mixed, hot pressed & 0.28 & 2.7 & $\begin{array}{c}1 \mathrm{E}+1 \\
@ 1 w t \%\end{array}$ & {$[74]$} \\
\hline $\begin{array}{c}\text { PE, } \\
\text { UHMW }\end{array}$ & $\begin{array}{c}\text { SWCNT (Arc, } \\
\text { high-grade) }\end{array}$ & $\mathrm{e}$ & - & - & - & dry mixed, hot pressed & 0.6 & 2.2 & $\begin{array}{c}5 \mathrm{E}-2 \\
@ 3 \mathrm{wt} \%\end{array}$ & [74] \\
\hline $\begin{array}{c}\text { PE, } \\
\text { UHMW }\end{array}$ & $\begin{array}{l}\text { SWCNT (Arc, } \\
\text { low-grade) }\end{array}$ & e & - & - & - & dry mixed, hot pressed & 1.1 & 2.3 & $\begin{array}{c}5 \mathrm{E}-1 \\
@ 3 \mathrm{wt} \%\end{array}$ & {$[74]$} \\
\hline $\begin{array}{c}\text { PE, } \\
\text { UHMW }\end{array}$ & $\begin{array}{l}\text { SWCNT (Arc), } \\
\text { CarboLex }\end{array}$ & e & - & - & - & dry mixed, hot pressed & 1.2 & 2.2 & $\begin{array}{c}5 E-3 \\
@ 3 w t \%\end{array}$ & [74] \\
\hline $\begin{array}{l}\mathrm{PE} \\
\mathrm{LD}\end{array}$ & MWCNT (CVD) & $\mathrm{e}$ & $\begin{array}{l}\mathrm{HCl} / \mathrm{HNO} 3, \\
\text { centrifuged }\end{array}$ & $\begin{array}{c}< \\
1000\end{array}$ & - & ball milled, hot pressed & 2 & - & $\begin{array}{c}3 E+0 \\
@ 10 w t \%\end{array}$ & {$[76]$} \\
\hline $\begin{array}{l}\mathrm{PE} \\
\mathrm{HD}\end{array}$ & $\begin{array}{l}\text { SWCNT (HiPco®), } \\
\text { Carbon Nanotech. }\end{array}$ & $\mathrm{e}$ & purified & - & $\mathrm{H} 2 \mathrm{O}, \mathrm{SDS}$ & $\begin{array}{l}\text { sonicated, centrifuged, } \\
\text { sprayed, extruded }\end{array}$ & 4 & - & $\begin{array}{c}5 \mathrm{E}-1 \\
@ 6 \mathrm{wt} \%\end{array}$ & {$[77]$} \\
\hline $\begin{array}{l}\mathrm{PE} \\
\mathrm{MD}\end{array}$ & $\begin{array}{l}\text { MWCNT (CVD), } \\
\text { Sun Nanotech }\end{array}$ & - & $\mathrm{HCl}$ & $>100$ & - & extruded & 7.5 & - & $\begin{array}{c}1 \mathrm{E}-2 \\
@ 10 \mathrm{wt} \%\end{array}$ & [78] \\
\hline
\end{tabular}




\begin{tabular}{|c|c|c|c|c|c|c|c|c|c|c|}
\hline $\begin{array}{l}\text { PE, } \\
\text { LD }\end{array}$ & $\begin{array}{c}\text { MWCNT (CVD), } \\
\text { Shenzhen Nanotech. }\end{array}$ & e & - & 100 & $\mathrm{C} 8 \mathrm{H} 10$ & sonicated, melt mixed & 15 & - & $\begin{array}{c}5 \mathrm{E}-6 \\
@ 30 \mathrm{wt} \% \\
\end{array}$ & [79] \\
\hline PEO & $\begin{array}{c}\text { MWCNT (CVD), } \\
\text { Nano-Lab }\end{array}$ & - & - & 1000 & $\mathrm{H} 2 \mathrm{O}, \mathrm{GA}$ & $\begin{array}{l}\text { sonicated, stirred, } \\
\text { electrospinned }\end{array}$ & 0.45 & 1.3 & - & [80] \\
\hline PEO & MWCNT (CVD) & - & HNO3 & - & C3H8O & stirred & $15-50$ & - & $\begin{array}{c}7 E+2 \\
@ 50 w t \%\end{array}$ & [81] \\
\hline PET & $\begin{array}{l}\text { SWCNT (Arc), } \\
\text { CarboLex }\end{array}$ & e & - & 1000 & - & extruded, hot pressed & 0.7 & - & $\begin{array}{c}1 \mathrm{E}-4 \\
@ 2 \mathrm{wt} \% \\
\end{array}$ & [82] \\
\hline PET & $\begin{array}{c}\text { MWCNT (CVD), } \\
\text { Shenzhen Nanotech. }\end{array}$ & e & $\mathrm{HCl}$ & 1000 & $\begin{array}{l}\text { ODCB- } \\
\mathrm{C} 6 \mathrm{H} 6 \mathrm{O} \\
\end{array}$ & sonicated & 0.9 & 2.2 & $\begin{array}{c}3 E-2 \\
@ 9 w t \% \\
\end{array}$ & [83] \\
\hline PFA & $\begin{array}{l}\text { MWCNT (CVD), } \\
\text { Showa Denko K.K. }\end{array}$ & - & anneal & $>30$ & - & $\begin{array}{c}\text { sonicated, stirred, } \\
\text { doctor blade }\end{array}$ & 8 & - & $\begin{array}{c}1 \mathrm{E}+1 \\
@ 15 \mathrm{wt} \% \\
\end{array}$ & [84] \\
\hline $\mathrm{PI}$ & $\begin{array}{l}\text { SWCNT (Laser), } \\
\text { Rice Univ. }\end{array}$ & e & - & $>300$ & $\mathrm{C} 6 \mathrm{H} 8 \mathrm{O}$ & sonicated, stirred & 0.05 & 1.5 & $\begin{array}{c}1 \mathrm{E}-4 \\
@ 1 \mathrm{wt} \%\end{array}$ & [85] \\
\hline $\mathrm{Pl}$ & $\begin{array}{l}\text { MWCNT (CVD), } \\
\text { Hyperion Catalysis }\end{array}$ & e & - & 1000 & C4H9NO & sonicated, stirred & 0.3 & 1.6 & $\begin{array}{c}1 \mathrm{E}+1 \\
@ 7.4 \mathrm{wt} \% \\
\end{array}$ & [86] \\
\hline $\mathrm{PI}$ & $\begin{array}{l}\text { MWCNT (CVD), } \\
\text { Sun Nanotech } \\
\end{array}$ & - & $\begin{array}{l}\mathrm{H} 2 \mathrm{SO} 4 / \mathrm{HNO} 3, \\
\text { centrifuged }\end{array}$ & 100 & C4H9NO & sonicated & 9.5 & - & $\begin{array}{l}2 \mathrm{E}-3 \\
@ 12 \text { wt\% }\end{array}$ & [87] \\
\hline PMMA & MWCNT (CVD) & ne & - & - & $\mathrm{C} 8 \mathrm{H} 18 \mathrm{O} 4$ & stirred, spincoated & 0.084 & 1.8 & $\begin{array}{l}2 E+2 \\
@ 1.5 w t \%\end{array}$ & [88] \\
\hline PMMA & $\begin{array}{l}\text { MWCNT, } \\
\text { NanoLab } \\
\end{array}$ & - & - & 1000 & $\begin{array}{l}\text { C2HF3O2, } \\
\text { C4H8O }\end{array}$ & sonicated & 0.12 & - & $\begin{array}{ll} & 8 \mathrm{E}-1 \\
@ & 1.5 \mathrm{wt} \% \\
\end{array}$ & [89] \\
\hline PMMA & $\begin{array}{l}\text { SWCNT (HiPcoß), } \\
\text { Carbon Nanotech. }\end{array}$ & e & $\mathrm{SOCl} 2$ & - & $\mathrm{CHCl} 3$ & stirred & 0.17 & 2.2 & $\begin{array}{l}1 E+4 \\
@ 10 w t \%\end{array}$ & [17] \\
\hline PMMA & $\begin{array}{l}\text { SWCNT (HiPcoß), } \\
\text { Carbon Nanotech. }\end{array}$ & e & - & - & $\mathrm{CHCl} 3$ & stirred & 0.17 & 1.3 & $\begin{array}{c}2 \mathrm{E}+3 \\
@ 10 \mathrm{wt} \%\end{array}$ & [17] \\
\hline PMMA & $\begin{array}{l}\text { MWCNT (CVD), } \\
\text { Iljin Nanotech. }\end{array}$ & e & - & - & $\mathrm{C} 7 \mathrm{H} 8$ & sonicated, stirred & 0.2 & 2.3 & $\begin{array}{c}1 \mathrm{E}+2 \\
@ 10 \mathrm{wt} \% \\
\end{array}$ & [21] \\
\hline PMMA & SWCNT (Arc) & e & - & - & $\mathrm{C} 7 \mathrm{H} 8$ & sonicated & 0.33 & 2.1 & $\begin{array}{c}5 E+1 \\
@ 8 w t \% \\
\end{array}$ & [90] \\
\hline PMMA & $\begin{array}{l}\text { SWCNT (HiPcoß), } \\
\text { Rice Univ. }\end{array}$ & e & $\begin{array}{l}\mathrm{HCl}, \mathrm{CH} 4 \mathrm{O}, \\
\text { annealed }\end{array}$ & 45 & $\mathrm{C} 6 \mathrm{H} 8 \mathrm{O}$ & $\begin{array}{l}\text { sonicated, } \mathrm{H} 2 \mathrm{O} \\
\text { (coagulation), } \\
\text { hot pressed }\end{array}$ & 0.37 & - & $\begin{array}{c}5 E-2 \\
@ 2 w t \%\end{array}$ & [14] \\
\hline
\end{tabular}




\begin{tabular}{|c|c|c|c|c|c|c|c|c|c|c|}
\hline PMMA & $\begin{array}{l}\text { SWCNT (HiPco®), } \\
\text { Rice Univ. }\end{array}$ & e & $\mathrm{HCl}$ & - & $\mathrm{C} 6 \mathrm{H} 8 \mathrm{O}$ & $\begin{array}{l}\text { sonicated, H2O } \\
\text { (coagulation), } \\
\text { hot pressed }\end{array}$ & 0.39 & 2.3 & $\begin{array}{c}1 \mathrm{E}-3 \\
@ 2 \mathrm{wt} \%\end{array}$ & [16] \\
\hline PMMA & SWCNT (Arc) & e & HNO3 & $\stackrel{>}{1000}$ & $\mathrm{C} 6 \mathrm{H} 8 \mathrm{O}$ & $\begin{array}{c}\text { sonicated, } \\
\text { wet-stretched, } \\
\text { hot pressed }\end{array}$ & 0.5 & - & $\begin{array}{c}1 \mathrm{E}-1 \\
@ 7 w t \% \\
\text { (parallel) }\end{array}$ & {$[91]$} \\
\hline PMMA & SWCNT (Arc) & e & HNO3 & $\stackrel{>}{1000}$ & $\mathrm{C} 6 \mathrm{H} 8 \mathrm{O}$ & $\begin{array}{c}\text { sonicated, } \\
\text { wet-stretched, } \\
\text { hot pressed }\end{array}$ & 0.5 & - & $\begin{array}{c}1 \mathrm{E}-5 \\
@ 7 \text { wt\% } \\
\text { (perp.) }\end{array}$ & {$[91]$} \\
\hline PMMA & $\begin{array}{l}\text { MWCNT, } \\
\text { Aldrich }\end{array}$ & - & $\begin{array}{c}\mathrm{C} 6 \mathrm{H} 8 \mathrm{O}, \mathrm{C} 2 \mathrm{HF} 3 \mathrm{O} 2, \\
\text { centrifugated }\end{array}$ & 100 & $\begin{array}{l}\text { C2HF3O2, } \\
\text { C4H8O }\end{array}$ & sonicated & 0.65 & - & $\begin{array}{ll} & 8 \mathrm{E}-2 \\
@ & 1.5 \mathrm{wt} \%\end{array}$ & [89] \\
\hline PMMA & $\begin{array}{l}\text { SWCNT (Arc), } \\
\text { CarboLex }\end{array}$ & e & - & - & $\mathrm{H} 2 \mathrm{O}, \mathrm{SDS}$ & $\begin{array}{c}\text { sonicated, centrifuged, } \\
\text { hot pressed }\end{array}$ & 0.7 & 2.0 & $\begin{array}{c}1 \mathrm{E}-1 \\
@ 1.5 \text { wt\% } \\
\end{array}$ & [92] \\
\hline PMMA & $\begin{array}{l}\text { SWCNT (HiPco®), } \\
\text { Rice Univ. }\end{array}$ & e & $\begin{array}{l}\mathrm{HCl}, \mathrm{CH} 4 \mathrm{O}, \\
\text { annealed }\end{array}$ & - & $\mathrm{C} 6 \mathrm{H} 8 \mathrm{O}$ & $\begin{array}{c}\text { sonicated, } \mathrm{H} 2 \mathrm{O} \\
\text { (coagulation), } \\
\text { hot pressed }\end{array}$ & 1.3 & - & $\begin{array}{c}1 \mathrm{E}-2 \\
@ 2 \mathrm{wt} \%\end{array}$ & [93] \\
\hline PMMA & $\begin{array}{l}\text { SWCNT (HiPcoß), } \\
\text { Aldrich }\end{array}$ & e & SOCl2 & - & $\mathrm{CHCl} 3$ & shaken, sonicated & $<0.1$ & - & $\begin{array}{c}5 E+1 \\
@ 0.5 \text { wt\% }\end{array}$ & {$[94]$} \\
\hline PmPV & MWCNT (Arc) & e & - & - & $\mathrm{C} 7 \mathrm{H} 8$ & sonicated & 0.06 & 1.4 & $\begin{array}{c}1 \mathrm{E}-5 \\
@ 4 \mathrm{wt} \%\end{array}$ & [95] \\
\hline PmPV & MWCNT (Arc) & e & - & $>25$ & $\mathrm{C} 7 \mathrm{H} 8$ & sonicated & 7.5 & - & $\begin{array}{c}2 \mathrm{E}-3 \\
@ 35 \mathrm{wt} \% \\
\end{array}$ & {$[96]$} \\
\hline PmPV & MWCNT (Arc) & e & - & - & $\mathrm{C} 7 \mathrm{H} 8$ & sonicated, spincoated & 8 & - & $\begin{array}{c}3 E+0 \\
@ 36 w t \% \\
\end{array}$ & [3] \\
\hline $\mathrm{PP}$ & MWCNT (CVD) & ne & - & 1000 & - & extruded & 0.07 & - & - & {$[97]$} \\
\hline PP & MWCNT (CVD) & - & - & - & - & sonicated, extruded & 0.4 & - & $\begin{array}{c}1 \mathrm{E}-1 \\
00.07 \text { wt\% } \\
\end{array}$ & [98] \\
\hline PP & $\begin{array}{c}\text { MWCNT, } \\
\text { Nanostr. and Amorph. } \\
\text { Mat. Inc. }\end{array}$ & - & - & - & - & $\begin{array}{l}\text { extruded (high shear), } \\
\text { hot pressed }\end{array}$ & 0.44 & - & $\begin{array}{c}2 E+0 \\
@ 9 w t \%\end{array}$ & [99] \\
\hline PP & $\begin{array}{l}\text { MWCNT (CVD), } \\
\text { Iljin Nanotech. }\end{array}$ & e & $\begin{array}{l}\mathrm{H} 2 \mathrm{SO} 4 / \mathrm{HNO} 3, \\
\text { filtrated }\end{array}$ & 1000 & - & extruded, hot pressed & 1.5 & - & $\begin{array}{c}2 \mathrm{E}-1 \\
@ 5 \mathrm{wt} \% \\
\end{array}$ & [100] \\
\hline PP & MWCNT (CVD) & - & $\mathrm{HF}, \mathrm{HCl}$ & - & - & extruded, hot pressed & 2 & - & $\begin{array}{c}5 \mathrm{E}-1 \\
@ 10 \text { wt\% }\end{array}$ & [101] \\
\hline
\end{tabular}


MWCNT,

PP Nanostr. and Amorph.

extruded (low shear),

hot pressed

$1 \mathrm{E}-4$

Mat. Inc.

hol p $2.6 \mathrm{wt} \%$

[99]

\begin{tabular}{|c|c|c|c|c|c|c|c|c|c|c|}
\hline PPV & SWCNT (Laser) & e & - & - & - & sonicated & 1.8 & 2.0 & $\begin{array}{c}1 \mathrm{E}+3 \\
@ 64 \mathrm{wt} \%\end{array}$ & [102] \\
\hline PS & $\begin{array}{l}\text { SWCNT (HiPcoß), } \\
\text { Carbon Nanotech. }\end{array}$ & e & PEE-functionalized & - & $\mathrm{CHCl} 3$ & shaken, sonicated & 0.05 & 1.5 & $\begin{array}{c}7 E+0 \\
@ 7 w t \%\end{array}$ & [65] \\
\hline PS & $\begin{array}{l}\text { MWCNT (CVD), } \\
\text { Arkema }\end{array}$ & e & - & $<60$ & $\mathrm{C} 6 \mathrm{H} 8 \mathrm{O}$ & sonicated, stirred & 0.16 & - & - & [103] \\
\hline PS & $\begin{array}{l}\text { SWCNT (Arc) } \\
\text { CarboLex }\end{array}$ & e & annealed & - & $\mathrm{C} 6 \mathrm{H} 4 \mathrm{Cl} 2$ & sonicated, stirred & 0.27 & 2.0 & $\begin{array}{c}1 \mathrm{E}-3 \\
@ 1 \mathrm{wt} \%\end{array}$ & [104] \\
\hline PS & $\begin{array}{l}\text { SWCNT (Arc), } \\
\text { CarboLex }\end{array}$ & e & - & - & $\mathrm{H} 2 \mathrm{O}, \mathrm{SDS}$ & $\begin{array}{l}\text { sonicated, centrifuged, } \\
\text { hot pressed }\end{array}$ & 0.28 & 1.6 & $\begin{array}{l}1 \mathrm{E}+0 \\
@ 1.5 w t \%\end{array}$ & [92] \\
\hline PS & $\begin{array}{l}\text { SWCNT (Arc) } \\
\text { CarboLex }\end{array}$ & e & - & - & $\mathrm{C} 6 \mathrm{H} 4 \mathrm{Cl} 2$ & sonicated, stirred & 0.44 & 3.6 & $\begin{array}{c}3 E-6 \\
@ 2 w t \%\end{array}$ & [104] \\
\hline PS & MWCNT (CVD) & ne & - & 1000 & - & extruded & 0.45 & - & - & [97] \\
\hline PS & $\begin{array}{l}\text { MWCNT (CVD), } \\
\text { Iljin Nanotech. }\end{array}$ & e & $\mathrm{HNO} 3, \mathrm{HCl}$ & - & - & sonicated & 0.8 & - & $\begin{array}{c}1 \mathrm{E}-2 \\
@ 2 \mathrm{wt} \%\end{array}$ & [105] \\
\hline PS & $\begin{array}{l}\text { SWCNT (Arc) } \\
\text { CarboLex }\end{array}$ & e & - & - & $\mathrm{H} 2 \mathrm{O}, \mathrm{GA}$ & $\begin{array}{c}\text { sonicated, centrifuged, } \\
\text { hot pressed }\end{array}$ & - & - & $\begin{array}{c}1 \mathrm{E}-6 \\
\text { @ } 3 \mathrm{wt} \% \\
\end{array}$ & [92] \\
\hline PS & BMWCNT (Arc) & e & $\mathrm{C} 3 \mathrm{H} 6 \mathrm{O}$, filtrated & - & $\mathrm{C} 7 \mathrm{H} 8$ & $\begin{array}{c}\text { sonicated, } \\
\text { hot pressed }\end{array}$ & $<12$ & - & $\begin{array}{c}1 \mathrm{E}+4 \\
@ 25 w t \%\end{array}$ & [106] \\
\hline PS & MWCNT (Arc) & e & $\mathrm{C} 3 \mathrm{H} 6 \mathrm{O}$, filtrated & - & $\mathrm{C} 7 \mathrm{H} 8$ & $\begin{array}{c}\text { sonicated, } \\
\text { hot pressed }\end{array}$ & $<12$ & - & $\begin{array}{c}3 E+2 \\
@ 25 w t \%\end{array}$ & [106] \\
\hline $\begin{array}{l}\text { PS- } \\
\text { Latex }\end{array}$ & $\begin{array}{l}\text { SWCNT (CoMoCAT®), } \\
\text { Soutwest Nanotech. }\end{array}$ & e & HF, filtrated & 2000 & $\begin{array}{c}\mathrm{H} 2 \mathrm{O}, \mathrm{AIBN} \\
\mathrm{C} 5 \mathrm{H} 8, \mathrm{SDBS}, \\
\mathrm{C} 16 \mathrm{H} 34\end{array}$ & $\begin{array}{l}\text { sonicated, stirred } \\
\text { (miniemulsion) }\end{array}$ & 0.2 & 7.3 & $\begin{array}{c}1 \mathrm{E}-4 \\
@ 3 \mathrm{wt} \%\end{array}$ & [107] \\
\hline $\begin{array}{l}\text { PS- } \\
\text { Latex }\end{array}$ & $\begin{array}{l}\text { SWCNT (CoMoCAT®), } \\
\text { Soutwest Nanotech. }\end{array}$ & e & HF, filtrated & 2000 & $\begin{array}{l}\mathrm{H} 2 \mathrm{O}, \mathrm{AIBN} \\
\mathrm{C} 5 \mathrm{H} 8, \mathrm{SDBS}\end{array}$ & $\begin{array}{l}\text { sonicated, stirred } \\
\text { (macroemulsion) }\end{array}$ & 0.2 & 7.6 & $\begin{array}{c}5 E-5 \\
\text { @ } 3 \text { wt\% }\end{array}$ & [107] \\
\hline $\begin{array}{l}\text { PS- } \\
\text { Latex }\end{array}$ & MWCNT (CVD) & e & HNO3 & $>100$ & $\mathrm{H} 2 \mathrm{O}$, SDBS & sonicated & 0.36 & 1.7 & $\begin{array}{c}1 E+1 \\
@ 6 w t \%\end{array}$ & [108] \\
\hline $\begin{array}{l}\text { PS- } \\
\text { Latex }\end{array}$ & MWCNT (CVD) & e & HNO3 & $>100$ & $\mathrm{H} 2 \mathrm{O}, \mathrm{SDBS}$ & $\begin{array}{c}\text { sonicated, freeze dried, } \\
\text { hot pressed }\end{array}$ & 0.9 & 3.9 & $\begin{array}{c}1 \mathrm{E}-1 \\
@ 6 w t \%\end{array}$ & [108] \\
\hline $\begin{array}{l}\text { PS- } \\
\text { Latex }\end{array}$ & $\begin{array}{l}\text { SWCNT (Arc) } \\
\text { CarboLex }\end{array}$ & $\mathrm{e}$ & - & 1000 & $\mathrm{H} 2 \mathrm{O}, \mathrm{SDS}$ & $\begin{array}{l}\text { sonicated, centrifuged, } \\
\text { hot pressed }\end{array}$ & 1.5 & 4.9 & $\begin{array}{c}5 E-3 \\
@ 5 w t \%\end{array}$ & [109] \\
\hline
\end{tabular}




\begin{tabular}{|c|c|c|c|c|c|c|c|c|c|c|}
\hline $\begin{array}{l}\text { PS- } \\
\text { Latex }\end{array}$ & MWCNT (CVD) & - & - & - & $\mathrm{H} 2 \mathrm{O}, \mathrm{SDS}$ & $\begin{array}{l}\text { sonicated, centrifuged, } \\
\text { stirred }\end{array}$ & 2.5 & - & $\begin{array}{c}1 \mathrm{E}+1 \\
@ 15 w t \%\end{array}$ & [110] \\
\hline $\mathrm{PU}$ & $\begin{array}{l}\text { MWCNT (CVD), } \\
\text { Iljin Nanotech. }\end{array}$ & $\mathrm{e}$ & oxidized & 1000 & MEK, BKC & $\begin{array}{l}\text { sonicated, stirred, } \\
\text { calendered }\end{array}$ & 0.018 & 1.5 & $\begin{array}{c}8 \mathrm{E}+0 \\
@ 8 w t \%\end{array}$ & [111] \\
\hline PU & $\begin{array}{c}\text { MWCNT, } \\
\text { Applied Science }\end{array}$ & - & - & $>100$ & $\mathrm{C} 4 \mathrm{H} 8 \mathrm{O}$ & stirred & 1 & 3.1 & $\begin{array}{c}2 E+3 \\
@ 15 w t \%\end{array}$ & [19] \\
\hline PVA & $\begin{array}{c}\text { MWCNT, } \\
\text { Ahwahnee Techn. Inc. }\end{array}$ & ne & $\begin{array}{l}\mathrm{H} 2 \mathrm{SO} 4 / \mathrm{HNO} 3, \\
\text { filtrated }\end{array}$ & - & $\mathrm{C} 6 \mathrm{H} 8 \mathrm{O}$ & $\begin{array}{l}\text { sonicated, stirred, } \\
\text { electrospinned }\end{array}$ & 0.2 & - & $\begin{array}{c}1 \mathrm{E}+1 \\
@ 5 w t \% \\
\end{array}$ & [112] \\
\hline PVA & $\begin{array}{c}\text { MWCNT (CVD), } \\
\text { Hyperion Catalysis }\end{array}$ & e & $\begin{array}{l}\mathrm{H} 2 \mathrm{SO} 4 / \mathrm{HNO} 3, \\
\text { filtrated }\end{array}$ & - & $\mathrm{H} 2 \mathrm{O}$ & stirred & $<10$ & - & $\begin{array}{c}1 \mathrm{E}+2 \\
@ 60 \mathrm{wt} \% \\
\end{array}$ & [113] \\
\hline $\begin{array}{l}\text { PVA- } \\
\text { Latex }\end{array}$ & $\begin{array}{l}\text { SWCNT (HiPcoß), } \\
\text { Carbon Nanotech. }\end{array}$ & e & - & - & $\mathrm{H} 2 \mathrm{O}, \mathrm{GA}$ & $\begin{array}{c}\text { sonicated, stirred, } \\
\text { filtrated }\end{array}$ & 0.038 & 1.9 & $\begin{array}{c}2 E+1 \\
@ 4 \text { wt\% }\end{array}$ & [114] \\
\hline PVC & $\begin{array}{l}\text { MWCNT (CVD), } \\
\text { TMSpetsmash Ltd. }\end{array}$ & - & - & 1000 & - & $\begin{array}{l}\text { stirred, grinded, } \\
\text { hot pressed }\end{array}$ & 0.094 & 3.3 & $\begin{array}{c}1 \mathrm{E}-2 \\
@ 1.4 \text { wt\% }\end{array}$ & [115] \\
\hline PVDF & $\begin{array}{c}\text { SWCNT, } \\
\text { Carbon Nanotech. }\end{array}$ & - & $\mathrm{H} 2 \mathrm{SO} 4$ & $\stackrel{>}{1000}$ & $\mathrm{C} 6 \mathrm{H} 8 \mathrm{O}$ & spincoated & 0.02 & - & $\begin{array}{c}3 E-4 \\
0.05 \text { wt } \%\end{array}$ & [116] \\
\hline PVDF & MWCNT & - & - & - & $\mathrm{C} 6 \mathrm{H} 8 \mathrm{O}$ & $\begin{array}{l}\text { sonicated, } \\
\text { hot pressed }\end{array}$ & 3.2 & 0.9 & $\begin{array}{c}2 E-4 \\
@ 4 w t \%\end{array}$ & [117] \\
\hline SPPA & MWCNT & - & - & - & - & sonicated & 3.5 & - & $\begin{array}{c}2 \mathrm{E}-1 \\
\text { @ } 20 \text { wt\% }\end{array}$ & [118] \\
\hline UPR & MWCNT (CVD) & - & annealed & - & - & $\begin{array}{l}\text { sonicated, } \\
\text { magnetic field }\end{array}$ & $<1$ & - & $\begin{array}{c}1 \mathrm{E}-1 \\
@ 1 w \mathrm{wt} \% \\
\text { (parallel) }\end{array}$ & [119] \\
\hline UPR & MWCNT (CVD) & - & annealed & - & - & $\begin{array}{l}\text { sonicated, } \\
\text { magnetic field }\end{array}$ & $<1$ & - & $\begin{array}{c}5 E-3 \\
@ 1 \text { wt\% } \\
\text { (perp.) } \\
\end{array}$ & [119] \\
\hline VE & MWCNT (CVD) & - & $\mathrm{NaOH}, \mathrm{HCl}, \mathrm{K} 2 \mathrm{MnO} 4$ & - & - & sonicated, stirred & $<0.5$ & - & $\begin{array}{c}4 \mathrm{E}-2 \\
@ 2 \mathrm{wt} \% \\
\end{array}$ & [120] \\
\hline VMQ & MWCNT & - & APTS-functionalized & 500 & - & hot pressed & 2.4 & 2.9 & $\begin{array}{c}4 \mathrm{E}-4 \\
@ 5 \mathrm{wt} \%\end{array}$ & [121] \\
\hline
\end{tabular}

